\title{
Reorganising the order Bacillales through phylogenomics
}

\author{
Pieter De Maayer $^{1 *}$, Habibu Aliyu ${ }^{2}$, Don A Cowan ${ }^{3}$ \\ ${ }^{1}$ School of Molecular \& Cell Biology, Faculty of Science, University of the Witwatersrand, South Africa \\ ${ }^{2}$ Technical Biology, Institute of Process Engineering in Life Sciences, Karlsruhe Institute of Technology, \\ Germany \\ ${ }^{3}$ Centre for Microbial Ecology and Genomics, University of Pretoria, South Africa \\ *Author for correspondence: pieter.demaayer@wits.ac.za
}

PDM: Pieter.demaayer@wits.ac.za

HA: $\underline{\text { Habibu.Aliqyu@partner.kit.edu }}$

DAC: Don.Cowan@up.ac.za

\begin{abstract}
Bacterial classification at higher taxonomic ranks such as the class, order and family levels is currently reliant on phylogenetic analysis with a single gene, 16S rRNA, and for some taxa, the presence of shared phenotypic characteristics. However, these may not be reflective of the true genotypic and phenotypic relationships of taxa. This is evident in the order Bacillales, members of which are broadly defined as aerobic, spore-forming and rod-shaped bacteria. However, some of the taxa in this order are anaerobic, do not produce spores and are coccoid in morphology. 16S rRNA gene phylogeny has also not been able to elucidate the taxonomic positions of a number of families incertae sedis within this order. Recently developed phylogenetic approaches based on the whole genome may provide a more accurate means to resolve higher taxonomic levels. Here we have applied a suite of phylogenomic approaches to re-evaluate the taxonomy of 80 representative taxa of eight families (and six family incertae sedis taxa) within the order Bacillales. This showed several anomalies within the existing family and order level classifications including the existence of four and two distinct Bacillaceae and Paenibacillaceae "family" clades, respectively. The analysis also supported the movement of the Staphylococcaceae and Listeriaceae to the sister order Lactobacillales. Finally, we propose a consensus phylogenomic approach which may diminish algorithmic biases associated with single phylogenomic approaches and facilitate a more accurate classification of a broad range of bacterial taxa at the higher taxonomic levels.
\end{abstract}




\section{Introduction}

With its inception in 1872 [1], the genus Bacillus became a veritable "dumping ground" for aerobic, endospore-forming bacteria. The subsequent development of enhanced taxonomic methodologies, including morphological, physiological, chemical and molecular approaches, resulted in considerable taxonomic changes, with the development of novel genera, families and higher rank taxonomic delineations to incorporate members of this genus and novel isolates of aerobic endospore-forming bacilli $[2,3]$. As such, the order Bacillales was proposed and subsequently validated on the basis of 16S rRNA gene sequence analysis [3-5]. Members of this order display a cosmopolitan functional and habitat distribution, including high temperature, extremely acidic, alkaline and hypersaline environments and incorporate clinical pathogens and strains of biotechnological value. One of the few consistent features of members of this order is the ability to form endospores, although exceptions do exist [4]. The order Bacillales currently comprises nine distinct families, Alicyclobacillaceae, Bacillaceae, Listeriaceae, Paenibacillaceae, Pasteuriaceae, Planococcaceae, Sporolactobacillaceae, Staphylococcaceae and Thermoactinomycetaceae, which incorporate a total of 133 genera. The largest of these is the family Bacillaceae, which includes 64 distinct genera [4, 6]. In addition, nine genera have been re-classified as families incertae sedis to reflect their ambiguous taxonomic delineation [4, 6]. In Bergey's Manual of Systematic Bacteriology Revised roadmap of the phylum Firmicutes, phylogenetic analysis on the basis of 16S rRNA gene sequences highlighted a number of discrepancies in the existing taxonomic scheme, with several of the families within the order Bacillales (e.g. Bacillaceae, Paenibacillaceae, Thermoactinomycetaceae) forming several distinct clades within the 16S rRNA gene phylogeny [4].

The poor resolving power at lower taxonomic levels, sequencing error, anomalies in sequences deposited in public nucleotide databases and the existence of multiple and often disparate copies in a single genome, have together sparked debate on the use of 16S rRNA gene sequences as a single marker for taxonomic delineation [7, 8]. However, given the paucity of comprehensive datasets of alternative taxonomic markers for polyphasic taxonomic approaches, 16S rRNA analysis remains the gold standard for higher level taxon delineation [4]. The development of next generation DNA sequencing technologies have led to a significant increase in the quantity and quality of sequence data at a greatly reduced cost [9]. The ability to utilise these improved technologies to sequence complete genomes has, more recently, led to their use for taxonomic delineation. Comparisons of genome sequences allows 
the establishment of a set of conserved core genes or proteins which can be used to define evolutionary relationships [10]. A subset of these proteins, the ribosomal biogenesis and maintenance proteins (RP), can also be extracted from the genome and used to construct phylogenies with far greater taxonomic resolution than is achievable using single gene phylogenies [11]. Furthermore, several phylogenomic metrics have been developed, such as average nucleotide identity (ANI) and average amino acid identity (AAI) values, digital DNADNA hybridization (dDDH) and tetranucleotide signature frequency correlation coefficient (TETRA) values. These phylogenomic metrics have been shown to correlate well with laboratory-based DNA-DNA hybridization (DDH) analyses which form the basis of valid species circumscription, with 95-96\% ANI, 90\% AAI, 70\% dDDH values and 0.99 TETRA values approximating the wet-lab DDH species boundary value of 70\% [12-14]. In contrast to laboratory-based DDH approaches, these tools provide highly reproducible results which can be readily validated by other researchers [15]. However, their use is largely restricted to taxonomic delineation at the species level, while limited tools are available for delineation at higher taxonomic levels. One exception is the Percentage of Conserved Proteins (POCP) approach, which has been proposed for circumscription at the genus level [16].

Here we have applied a suite of phylogenomic approaches to re-examine the taxonomic status of the order Bacillales, using a comprehensive set of strains representative of seventy-seven distinct genera and eight families within the order. Furthermore, we have adopted a consensus or polyphasic system incorporating the data from the different phylogenomic analyses to diminish algorithmic biases associated with each individual approach. Together, these data support several re-classifications which should be considered for the order Bacillales.

\section{Materials and Methods}

\section{Bacillales genomes}

The genomes of the type strains of type species of sixty-seven distinct genera within the order Bacillales (Table 1) were retrieved from the NCBI Genbank assembly database [17]. For a further nineteen genera, genomes were available for type strains of other species within the genera (Table 1). These were only incorporated in the analysis if their 16S rRNA gene sequences shared nucleotide identities with those of the type strain of the type species for the genus of $>95 \%$, which represents the prescribed cut-off value for incorporation in the same genus [18]. In addition, the genomes of type strains of the type genera for five families from 
the sister order Lactobacillales were included in the analyses, as well as the genome of Clostridium butyricum DSM 10702 ${ }^{\mathrm{T}}$ (order Clostridiales), which was used as outgroup for all analyses. The 16S rRNA gene sequences for each analysed strain were obtained from the NCBI nucleotide database [17]. Metadata relating to the morphology (cell shape), physiology (motility, ability to form spores), growth conditions (salt concentrations, temperature and $\mathrm{pH}$ range) and sources of isolation were obtained from the original species descriptions (Supplementary Table S1). All genomes were structurally annotated using Prokaryotic Genemark.hmm [19]. The resultant amino acid sequences were subjected to Orthofinder [20]. The ribosomal protein (RP) amino acid sequences from Bacillus subtilis 168 were extracted from the RiboDB database v 1.4.1 [21]. Local BlastP and tBlastN analyses were performed in Bioedit v. 7.2.5 [22] with this dataset to identify orthologous ribosomal proteins in each of the compared genomes.

\section{Phylogenomic metric calculations}

Average nucleotide identity values were calculated using OrthoANI (Supplementary Table S2) [23]. This algorithm calculates ANI values on the basis of orthologous fragment pairs only and is thus reported to provide more accurate values when genomes are reciprocally compared than traditional ANI calculations [23]. Average amino acid identity (AAI) values were determined using the aai.rb script in the enveomics package, using the two-way AAI option (Supplementary Table S3) [24]. Tetranucleotide usage (TETRA) pattern analyses (Supplementary Table S4) were performed with Jspecies v. 1.2.1 [25]. Using the Genome-toGenome Distance Calculator (GGDC 2.0) with formula 2, digital DNA-DNA hybridization values $(\mathrm{dDDH})$ values were calculated (Supplementary Table S5) [14]. These metrics are all applied to distinguish strains at the species level. A newly developed metric, Percentage Of Conserved Proteins (POCP), can be used for genus level circumscription, where POCP values $<50 \%$ indicate organisms belong to distinct genera [16]. POCP values were calculated using the formula $[(\mathrm{C} 1+\mathrm{C} 2) /(\mathrm{T} 1+\mathrm{T} 2) \times 100$, where $\mathrm{C} 1$ and $\mathrm{C} 2$ represents the number of conserved proteins (amino acid identity $>40 \%$ with alignment coverage $>50 \%$ ) and $\mathrm{T} 1$ and $\mathrm{T} 2$ represent the total number of proteins encoded on each genome (Supplementary Table S6) [16].

\section{Phylogenetic analyses}

The 16S rRNA gene sequences for each of the compared genomes were aligned using the MCoffee algorithm within the T-Coffee package, which incorporates several different multiple sequence alignment methods and combines the results in a single optimal alignment [26]. The 
114 core proteins (CPs) identified with Orthofinder, and the 45 conserved ribosomal proteins (RPs) were individually aligned using M-Coffee [24]. Subsequently the CP and RP alignments were concatenated in two distinct $\mathrm{CP}$ and RP datasets and poorly aligned positions were eliminated using GBlocks v 0.91b [27]. The 16S rRNA (1,061 nucleotide sites) and trimmed CP (22,049 amino acid sites) and RP (5,250 amino acid sites) alignments were used to construct Maximum Likelihood (ML) phylogenies using the PhyML 3.0 server [28] with the Smart Model Selection (SMS) option to determine the optimal substitution model for the alignment on the basis of the Akaike Information Criterion [29]. For the 16S rRNA gene ML phylogeny bootstrap analysis $(n=1,000)$ was performed to provide branch support, while for the CP and RP ML phylogenies branch support was determined using the Shimodaira-Hasegawa approximate Likelihood Ratio Test (SH-aLRT) method [30]. The percentage (ANI, AAI, $\mathrm{dDDH}, \mathrm{POCP}$ ) and decimal regression (TETRA) values from the phylogenomic metric calculations were converted into distance values [1- $(\%$ similarity/100)]. The resulting distance matrices were used to generate Neighbour Joining (NJ) trees with PHYLIP v 3.695 [31]. The tree topologies of the three sequence-based (CP, RP and 16S rRNA) and five phylogenomic metric (AAI, OrthoANI, POCP, TETRA) distance-based trees were pair-wise compared using Compare2Trees [32]. This program matches up the branches between two compared trees and calculates a topological score expressed as the percentage of branches which are identical between two given trees [32]. Six phylogenies (CP, RP, 16S rRNA, OrthoANI, AAI and POCP) which shared an overall topology score of $>50 \%$ were selected and used to generate a consensus dendrogram using the Consense algorithm in PHYLIP [31].

\section{Results}

\section{Constructing a consensus phylogenomic framework for the order Bacillales}

Representatives of 86 out of 144 genera within the order Bacillales for which genome sequences are available were analysed using core protein $(\mathrm{CP})$ and ribosomal protein (RP) phylogenies as well as a range of phylogenomic metrics. Initial comparison of the CP and 16S rRNA phylogenies (Figure 1) showed substantial congruence between the two phylogenies (tree topology score: $77.6 \%$ ). Differences between these phylogenies can largely be attributed to swapping of branches among the deeper nodes, although there is some swapping at the higher taxonomic ranks, particularly when considering the family incertae sedis strains (Figure 1). Superior congruence was observed between the CP and RP phylogenies (Figure 1 and 
Supplementary Figures S1), with a tree topology score of 91.2\% (Figure 2). Here, family incertae sedis members also clustered differently between the two phylogenies. The NJ trees constructed on the basis of the phylogenomic metrics AAI, POCP and OrthoANI (Supplementary Figures S2, S3 and S4) shared tree topology scores ranging from 67.6 to $81.5 \%$ among them and the CP, RP and 16S rRNA phylogenies (Figure 2). By contrast, the TETRA and dDDH tree topologies (Supplementary Figures S5 and S6) were incongruent with those of the other phylogenomic metric and alignment-based methodologies, with average tree topology scores of 40.4 and $25.3 \%$, respectively, suggesting that these approaches are not suitable for delineation of higher taxonomic ranks (Figure 2). The other phylogenomic metric- and sequence alignment-based phylogenies may also be subject to biases resulting in artefactual groupings which may be responsible for the incongruencies observed among the tree topologies. These include compositional biases where phylogenetically disparate taxa are grouped together due to similar nucleotide or protein compositions, heterotachy linked to variations in the evolutionary rates of particular amino acids and nucleotides in a given protein or gene, as well as long-branch attraction due to the higher evolutionary rates that may occur in some unrelated taxa $[10,33]$. To minimise the effects of these biases, a consensus tree was constructed on those phylogenomic metric and alignment-based phylogenies which shared tree topology scores of $>65.0 \%$, namely the CP, RP, $16 \mathrm{~S}$ rRNA, AAI, OrthoANI and POCP. The resultant cladogram (Figure 3 ) shared tree topology scores of $>78.3 \%$ with these six analyses. In particular, the topology of the consensus tree is most congruent with the CP (92.7\%) and RP (91.2\%) phylogenies. Although this cladogram based on the majority rule consensus of the different phylogenies does not consider the evolutionary distances between taxa, it gives a robust indication of the clustering patterns of the different taxa with reduced biasing effects compared to the individual phylogenies. The consensus tree also shares $78.9 \%$ tree topology score with the 16S rRNA gene phylogeny. As such, the family-level delineations in the consensus tree largely agree with the classifications at the family level on the basis of $16 \mathrm{~S}$ rRNA gene sequences [4]. This is true for several families, including the Listeriaceae, Staphylococcaceae, Planococcaceae, Thermoactinomycetaceae and Alicyclobacillaceae, as well as the order Lactobacillales which was included as outgroup. However, several discrepancies can be observed both in the consensus tree as well as the individual sequence alignment- and phylogenomic metric-based analyses. 
De Maayer et al. 2018 Systematic and Applied Microbiology

\section{The family Bacillaceae comprises four distinct "family" clades}

In the "revised road map to the phylum Firmicutes", it was shown that on the basis of $16 \mathrm{~S}$ rRNA gene phylogeny, the family Bacillaceae occurred in two distinct clades, where the first clade (Bacillaeceae 1) incorporated the type genus Bacillus, along with Geobacillus and Anoxybacillus, while the second (Bacillaceae 2) was comprised of eighteen genera [4]. Our phylogenomic analyses show that the majority of taxa belonging to this original family fall into four well-supported clades (Figure 3). The first clade, Bacillaceae 1 incorporates six genera, Aeribacillus, Anoxybacillus, Caldibacillus, Geobacillus and Parageobacillus along with the type genus strain B. subtilis DSM 10 . A second well-supported clade (Bacillaceae 2) is comprised of twenty genera, while the third (Bacillaceae 3) and fourth (Bacillaceae 4) incorporate eight and two genera, respectively (Figure 3). Among the taxa of the Bacillaceae 3, Sinobaca qinghaiensis DSM $17008^{\mathrm{T}}$ was previously described as a member of the family Sporolactobacillaceae [34]. The four Bacillaceae clades in the consensus tree are fully supported by the CP, RP and AAI trees (Figure 3; Supplementary Figures S1 and S2), with intra-clade AAI values ranging between 55.15 and $60.46 \%$ and inter-clade values between 48.43 and 52.88\%. While these four clades are also evident in the OrthoANI tree (Supplementary Figure S4), the Bacillaceae 1 clade in this tree also incorporates Domibacillus robiginosus DSM $25058^{\mathrm{T}}$ and Jeotgalibacillus alimentarius DSM $18867^{\mathrm{T}}$, which form part of the Planocococcaceae clade in the CP, 16S rRNA, AAI and consensus trees. In the POCP tree (Supplementary Figure S3), D. robiginosus DSM $25058^{\mathrm{T}}$ again clusters with the Bacillaceae 1 clade, while the Bacillaceae 1 strain C. debilis DSM $16016^{\mathrm{T}}$ clusters with the Sporolactobacillaceae. In the original descriptive paper, D. robiginosus was characterised as a borderline strain between the Bacillaceae and Planococcaceae [35], which may explain the clustering of this strain with the Bacillaceae 1 in the OrthoANI and POCP tree (Supplementary Figures S3 and S4) and with the Planococcaceae in the CP, 16S rRNA and AAI trees (Figure 1 and Supplementary Figure S1). On the basis of the consensus tree, however, D. robiginosus DSM $25058^{\mathrm{T}}$ clusters on the outside of the Planococcaeae clade along with $J$. alimentarius DSM $18867^{\mathrm{T}}$, which forms a clade with the other Planococcaceae in five (all except the OrthoANI tree) trees, and as such, D. robiginosus should be considered as a member of the family Planococcaceae. The incorporation of additional Domibacillus species in the phylogenomic analysis may further clarify its taxonomic position.

Analysis of the available species description metadata revealed few distinguishing morphological and phenotypic characteristics for the four Bacillaceae clades. The Bacillaceae 
clades 1-3 incorporate both facultative and obligate aerobic taxa, while Bacillaceae clade 3 incorporates the strict anaerobe A. arseniciselenatis DSM $15340^{\mathrm{T}}$ and clade 4 includes the microaerophilic Tepidibacillus decaturensis DSM $103037^{\mathrm{T}}$ and the strict anaerobe Vulcanibacillus modesticaldus DSM $14931^{\mathrm{T}}$. The Bacillaceae clades 2-3 also include both motile and non-motile rod-shaped, spore-forming and non-spore forming taxa and some taxa in these clades can tolerate higher salt concentrations (Supplementary Table S1). The Bacillaceae 1 (with the exception of B. subtilis DSM 10 ${ }^{\mathrm{T}}$ ) and 4 clades are composed primarily of thermophilic taxa, while the Bacillaceae 2 and 3 clades contain mesophilic taxa. Our phylogenomic analyses, however, clearly differentiate the Bacillaceae into four distinct clades, which may represent four distinct families. Comprehensive phenotypic analyses may reveal additional distinguishing features for this taxonomic delineation.

While twenty-five of the compared Bacillaceae are placed within the Bacillaceae 1-4 clades, a further four strains are placed elsewhere in the consensus tree (Figure 3). Aside from $D$. robiginosus DSM $25058^{\mathrm{T}}$ which, as discussed above, clusters on the outside of the Planococcaceae clade, three other strains, namely Viridibacillus arvi DSM $16317^{\mathrm{T}}$, Lysinibacillus boronitolerans DSM $17140^{\mathrm{T}}$ and Psychrobacillus psychrodurans DSM $11713^{\mathrm{T}}$ consistently cluster with the Planococcaceae in the CP, RP, 16S rRNA, AAI, POCP and OrthoANI trees (Figure 1 and Supplementary Figures S1, S2, S3 and S4) and should thus be considered as members of this family. The incorporation of four members of the Bacillaceae, along with two members of the families incertae sedis (discussed below) in the family Planococcaceae suggest that this family is much larger than previously appreciated. As observed with the Bacillaceae, available metadata reveal no consistent phenotype that may distinguish members of this family, as it includes both obligate aerobic and facultative anaerobic, coccoid or rod-shaped, spore and non-spore forming, motile and non-motile, as well as mesophilic and some psychrophilic taxa. Further phenotypic characterization inclusive of the Bacillaceae and family incertae sedis taxa that should be reclassified to the Planococcaceae may identify features unique to this family.

\section{The Paenibacillaceae comprise two distinct 'family' clades}

Seven representative strains of the family Paenibacillaceae were included in this study. These representatives were observed to form part of two distinct clades in the consensus tree, the Paenibacillaceae 1 (including the type genus Paenibacillus) and 2, comprising of five and two strains, respectively (Figure 3). These distinct clades are spatially separated in four of the six 
De Maayer et al. 2018 Systematic and Applied Microbiology

phylogenies incorporated in the consensus tree, namely the CP, RP, 16S rRNA and AAI trees (Figure 1 and Supplementary Figures S1 and S4). In the other trees (POCP and OrthoANI), the Paenibacillaceae 1 and 2 strains form part of a single clade, but occur in two distinct branches within these trees. The Paenibacillaceae may thus be split into two distinct family clades; the Paenibacillaceae 1 (Cohnella thermotolerans DSM 17683' , Thermobacillus composti DSM $18247^{\mathrm{T}}$, Fontibacillus panacisegetis DSM 28129 , Paenibacillus polymyxa DSM $36^{\mathrm{T}}$ and Saccharibacillus sacchari DSM 19268 ) and the Paenibacillaceae 2 (Aneurinibacillus migulanus DSM $2895^{\mathrm{T}}$ and Brevibacillus formosus DSM 9885 $\mathrm{T}$ ). This partially agrees with the previous observation of two monophyletic clades being formed in a $16 \mathrm{~S}$ rRNA phylogeny, although Brevibacillus clustered with Paenibacillus, Thermobacillus and Cohnella, while Aneurinibacillus clustered with Ammoniphilus and Oxalophagus (for which no genomes are available) in the earlier study [36]. While both the Paenibacillaceae 1 and 2 clades incorporate aerobic, spore-forming, motile rods, their separation is supported by genomic characteristics (Table 1). The Paenibacillaceae 1 have genomes which are, on average, $945 \mathrm{~kb}$ larger, and with a mean $\mathrm{G}+\mathrm{C}$ content of $6.54 \%$ below that of the Paenibacillaceae 2 (average genome size: $5.34 \mathrm{Mb}$; average $\mathrm{G}+\mathrm{C}$ content: $51.78 \%$ ).

\section{The families Listeriaceae and Staphylococcaceae belong to the order Lactobacillales}

The consensus tree shows the taxa belonging to the families Listeriaceae (Brochothrix thermosphacta DSM 20171 ${ }^{\mathrm{T}}$ and Listeria monocytogenes DSM 20600 ${ }^{\mathrm{T}}$ ) and Staphylococcaceae (Staphylococcus aureus DSM 20231 ${ }^{\mathrm{T}}$, Aliicoccus persicus DSM 28306 ${ }^{\mathrm{T}}$, Salinicoccus luteus DSM $17002^{\mathrm{T}}$ and Jeotgalicoccus psychrophilus DSM 19085 ${ }^{\mathrm{T}}$ ) clustering with representatives of the order Lactobacillales (Figure 3). This clustering pattern is also observed in the CP and 16S rRNA phylogenies (Figure 1) and the POCP and OrthoANI trees (Supplementary Figures S3 and S4). In the RP phylogeny (Supplementary Figure S1) the Listeriaceae cluster with the Lactobacillales while the Staphylococcaceae form a separate clade closer to the Planococcaceae. In the AAI tree (Supplementary Figure S2), the Lactobacillales, Listeriaceae and Staphlyococcaceae form part of three distinct clades. The co-clustering of these two Bacillales families with the Lactobacillales observed in most of the trees is further supported by both phenotypic and genotypic features of members of both of these families. As with the Lactobacillales, the Staphylococcaceae and Listeriaceae families incorporate taxa with a coccoid morphology, rather than the rod-shaped morphology typical of the Bacillales. The genomes of the Listeriaceae (2.68 Mb average) and Staphylococcaceae (2.43 Mb average) are more similar in size to those of the Lactobacillales (2.26 Mb average) than the Bacillales 
(3.76 $\mathrm{Mb}$ average) and the $\mathrm{G}+\mathrm{C}$ contents of the Listeriaceae (37.17\%) and Staphylococcaceae $(40.18 \%)$ are more similar to those of the Lactobacillales $(39.63 \%)$ than those of the Bacillales (44.0\%). Taken together, these data provide support for the reclassification of the families Listeriaceae and Staphylococcaceae within the order Lactobacillales, rather than within the order Bacillales.

\section{Taxonomic placement of the Bacillales families incertae sedis}

The order Bacillales incorporates nine genera which have not been taxonomically classified at the family level. Six representatives of these family incertae sedis taxa were incorporated in the phylogenomic analyses. Solibacillus silvestris DSM $12223^{\mathrm{T}}$ and Rummeliibacillus pycnus DSM $15030^{\mathrm{T}}$ cluster with the Planococcaceae in all phylogenomic analyses. The former strain consistently clusters with Caryophanon latum DSM $14151^{\mathrm{T}}$, while the latter clusters with Kurthia zopfii DSM $20580^{\mathrm{T}}$. As such, these taxa, along with four members of the family Bacillaceae, should be reclassified to the family Planococcaceae. The family XI incertae sedis strain Gemella haemolysans ATCC $10379^{\mathrm{T}}$ clusters on the outside of the Staphylococcaceae branch, where it was previously assigned [37], in the CP, RP and 16S rRNA phylogenies and the OrthoANI tree (Figure 1 and Supplementary Figures S1 and S4). This strain has a relatively small genome (1.92 Mb in size) and its cells are coccoid in shape, and as such, this strain should be reclassified along with the Listeriaceae and Staphylococcaceae as a member of the order Lactobacillales, as has previously been suggested in a broader-scale phylogenomic analysis of the phylum Firmicutes [38]. Aside from its clustering on the outside of the Staphylococcaceae clade, Gemella also clusters with the Lactobacillales taxa in the POCP tree (Supplementary Figure S3) and therefore may form a distinct family clade in the order Lactobacillales.

The taxonomic positions of the other three family incertae sedis, namely Exiguobacterium aurantiacum DSM 6208 ${ }^{\mathrm{T}}$, Thermicanus aegypticus DSM $12793^{\mathrm{T}}$ and Desulfuribacillus alkaliarsenatis DSM $24608^{\mathrm{T}}$ are less clearly defined. The consensus phylogeny places $E$. aurantiacum DSM $6208^{\mathrm{T}}$ (Family XII) with the Sporolactobacillaceae, a clustering pattern also observed in the CP and RP phylogenies (Figure 1 and Supplementary Figure S1), but distinct positions are observed for this strain in the POCP and OrthoANI (clusters with Lactobacillales, Staphylococcaceae and Listeriaceae), AAI (clusters separately) and 16S rRNA (clusters with the Paenibacillaceae 2) trees. Similarly, T. aegypticus DSM $12793^{\mathrm{T}}$ (Family X) clusters with the Alicyclobacillaceae in the OrthoANI and AAI trees, with the Bacillaceae 4 in the POCP tree, on its own in the RP phylogeny and with the Thermoactinomycetaceae in the 16S rRNA 
phylogeny. The CP phylogeny show this strain to be associated with the family Paenibacillaceae, where it was classified before transfer of Thermicanus to Family X incertae sedis [37]. Desulfuribacillus alkaliarsenatis DSM $24608^{\mathrm{T}}$ clusters with the Bacillaceae 4 strains in the AAI and POCP trees (Supplementary Figures S2 and S3). In the CP, RP, 16S rRNA phylogeny and the OrthoANI tree (Figure 1 and Supplementary Figures S1 and S4), this strain forms a distinct branch near the base of the tree, suggesting it forms part of a novel family distantly related to the other Bacillales. The disparate clustering for these family incertae sedis taxa between the different phylogenies and phylogenomic metric trees indicate that at least some of these techniques are prone to compositional biases and long-branch attraction which may not be effectively diluted in the consensus phylogeny, and as such their taxonomy cannot currently be accurately resolved. However, the incorporation of additional genomes, including those of other species for these genera, in this phylogenomic approach may elucidate the correct taxonomic position of these taxa.

\section{Discussion}

The accurate classification of bacterial taxa at the genus and species levels remains a difficult task. This is even more complicated at the higher taxonomic levels, including the family and order levels, where techniques such as DNA-DNA hybridization are not feasible. Furthermore, inconsistencies are frequently observed within 16S rRNA gene phylogenies and shared phenotypic characteristics between these higher level taxonomic ranks, resulting in a highly subjective classification scheme [12]. This is highlighted by the family Bacillaceae which was circumscribed to incorporate aerobic or facultatively anaerobic, chemo-organotrophic, endospore-forming Gram-positive rods [39]. This family was consolidated on the basis of 16S rRNA phylogeny [4], even though it incorporates taxa which are strictly anaerobic, non-sporeforming and have a coccoid morphology. As the 16S rRNA gene may not be representative of the phenotype or genotype of an organism [12], the development of a more robust system for higher taxonomic rank classification is an imperative.

Here we have employed phylogenomic methodologies, incorporating techniques that consider the genome at both the nucleotide and amino acid levels, to address the taxonomy of the order Bacillales. This genome-level analysis has revealed several taxonomic considerations, including the clustering of members of the family Bacillaceae in three distinct "family" clades, the existence of two Paenibacillaceae "family" clades and the grouping of the families Staphylococcaceae and Listeriaceae with the order Lactobacillales, rather than the order 
Bacillales. Discrepancies in the results from the different phylogenomic analyses highlight the danger of using a single methodology to resolve taxonomy. For this reason, we have adopted a consensus phylogenomic approach, using polyphasic genomic methods for bacterial classification and diluting the effects of algorithmic biases associated with individual techniques. This robust, yet simple, methodology can easily be applied to resolve the classification of a broad range of bacterial taxa at all taxonomic levels.

One significant issue observed in these analyses was the taxonomic position of members of the Bacillales families incertae sedis, which had a profound influence on the variability of the phylogenomic analyses. The different clustering patterns observed may be due to the effects of long-branch attraction and compositional biases associated with the individual phylogenomic metrics. Their positions may be more accurately resolved by the incorporation of additional taxa within the families incertae sedis. By the same token, the inclusion of multiple species from the different genera incorporated in the analyses may better resolve the order Bacillales at the family, genus and species levels.

\section{Figure and Tables}

Table 1: Genomic properties of the compared Bacillales taxa. The strains incorporated in this study are listed along with the NCBI accession numbers for the genomes, number of contigs, genome sizes, average genomic $\mathrm{G}+\mathrm{C}$ content and number of proteins encoded on the genome. For some genera the genome of the type strain of the type species was unavailable. The relative 16S rRNA sequence identity of a representative species type strain to the type species type strain for that genus is shown. Only those strains with 16S rRNA gene sequence identities $>95 \%$ were selected for incorporation in the analyses.

\section{Figure 1: Comparison of a core protein (CP) phylogeny and 16S rRNA gene phylogeny} of the order Bacillales. Maximum likelihood phylogenies were constructed on the basis of 114 concatenated core proteins (22,049 amino acid sites) and the 16S rRNA gene $(1,061$ nucleotide sites) using PhyML-SMS [28, 29], with the optimal substitution models of LG+G+I and $\mathrm{GTR}+\mathrm{G}+\mathrm{I}$, respectively. The representative taxa are coloured according to their original family designation where members of the Lactobacillales are coloured in dark blue, Listeriaceae in pink, Staphylococcaceae in blue, Planococcaceae in purple, Bacillaceae in red, Sporolactobacillaceae in grey, Planococcaceae in green, Thermoactinomycetaceae in maroon, 
Alicyclobacillaceae in teal and families incertae sedis in olive. Solid connecting lines indicate where taxa cluster in the same "Family" clades in both the CP and 16S rRNA gene phylogenies, while dotted lines indicate where distinct clustering patterns are observed. Bootstrap values (n $=1,000$ replicates) and Shimodaira-Hasegawa approximate Likelihood Ratio Test (SH-aLRT) values [30] are shown on the branches of the 16S rRNA and CP phylogenies, respectively.

Figure 2: Tree topology congruence scores (\%) for the different phylogenomic analyses. Tree topology congruence scores were determined using Compare2Trees [32]. The dendrogram on the left was constructed on the basis of the \% topology congruence converted into distance values. Phylogenomic approaches highlighted in green were utilised to construct the consensus phylogeny, while those highlighted in red were excluded.

Figure 3: Consensus tree constructed on the basis of six alignment- and phylogenomic metric-based approaches. Taxa are coloured according to their original family designations (as in Figure 1). The consensus tree was constructed using the Consense script in PHYLIP v 3.695 [31]. Values on the branches indicate the number of times taxa nodes co-occur in branches in the six trees (CP, RP, 16S rRNA, AAI, OrthoANI, POCP) incorporated in the consensus tree. For example $4 / 6$ denotes congruence in four out of the six approaches. Only those clades supported in $\geq 3 / 6$ trees are shown.

\section{Supplementary Data}

Supplementary Table S1: Metadata of the compared Bacillales taxa. The metadata relating to the growth conditions (range and optimum salt concentrations, range and optimum $\mathrm{pH}$, range and optimum temperature $)$, physiology $\left(\mathrm{O}_{2}\right.$ requirement, motility, spore formation) and source of isolation were derived from the original species and genus descriptions.

Supplementary Table S2: Average nucleotide identity (ANI) values. ANI values were calculated with OrthoANI [23] and are expressed as a percentage.

Supplementary Table S3: Average amino acid identity (AAI) values. Two-way AAI values were calculated using the aai.rb script which is part of the Enveomics package [24] and are expressed as a percentage. 
Supplementary Table S4: Tetranucleotide signature frequency correlation coefficient (TETRA) values. The values are expressed as a proportion and were calculated using Jspecies v 1.2.1 [25].

Supplementary Table S5: digital DNA-DNA Hydridization (dDDH) values. These values were derived through the Genome-to-Genome Distance Calculator (GGDC) 2.1 server [14] and are expressed as a percentage.

Supplementary Table S6: Percentage Of Conserved Proteins (POCP) values. Orthologous proteins conserved among pair-wise compared genomic protein datasets were used to calculated POCP by the formula $(\mathrm{C} 1+\mathrm{C} 2) /(\mathrm{T} 1+\mathrm{T} 2)$, with $\mathrm{C} 1$ and $\mathrm{C} 2$ representing the number of conserved proteins and T1 and T2 the total number of proteins per genome [16].

Supplementary Figure S1: Ribosomal protein ML phylogeny. The Maximum likelihood phylogeny was constructed on the basis of 45 concatenated conserved ribosomal proteins (5,250 amino acid sites) using PhyML-SMS [28, 29], with the optimal predicted amino acid substitution model $\mathrm{LG}+\mathrm{G}+\mathrm{I}$. Taxa are coloured according to their original family designations (as in Figure 1). SH-aLRT support values [30] are shown on the branches.

Supplementary Figure S2: NJ tree on the basis of AAI values. AAI values were converted into distance values by the formula: 1 - $(\% \mathrm{AAI} / 100)$ and used to construct a NJ tree using PHYLIP v 3.695 [31]. Taxa and branches are coloured according to their original family designations (as in Figure 1).

Supplementary Figure S3: NJ tree on the basis of POCP values. POCP values were converted into distance values by the formula: $1-(\% \mathrm{POCP} / 100)$ and used to construct a NJ tree using PHYLIP v 3.695 [31]. Taxa and branches are coloured according to their original family designations (as in Figure 1).

Supplementary Figure S4: NJ tree on the basis of OrthoANI values. OrthoANI values were converted into distance values by the formula: $1-(\%$ OrthoANI/100) and used to construct a NJ tree using PHYLIP v 3.695 [31]. Taxa and branches are coloured according to their original family designations (as in Figure 1).

Supplementary Figure S5: NJ tree on the basis of TETRA values. TETRA values were converted into distance values by the formula: 1 - TETRA score and used to construct a NJ tree using PHYLIP v 3.695 [31]. Taxa and branches are coloured according to their original family designations (as in Figure 1). 
Supplementary Figure S6: NJ tree on the basis of dDDH values. dDDH values were converted into distance values by the formula: $1-(\% \mathrm{dDDH} / 100)$ and used to construct a NJ tree using PHYLIP v 3.695 [31]. Taxa and branches are coloured according to their original family designations (as in Figure 1).

\section{Authors' contributions}

PDM, HA and DAC conceived the study. PDM and HA performed data analyses. PDM wrote the original manuscript and all authors contributed to the final version. All authors have read and approved the final manuscript.

\section{Competing interests}

The authors declare that they have no competing interests.

\section{Acknowledgements}

PDM acknowledges funding from the University of the Witwatersrand Faculty Research Council (FRC) and HA acknowledges the University of Pretoria for postdoctoral funding.

\section{References}

[1] Cohn, F. (1872) Untersuchungen über Bakterien, Beitr. Biol. Pflanz. 1, 127-224.

[2] Fritze, D. (2004) Taxonomy of the genus Bacillus and related genera: the aerobic endospore-forming bacteria. Phytopathology 94, 1245-1248.

[3] Garrity, G.M., Bell, J.A., Lilburn, T.G. (2004) Taxonomic outline of the prokaryotes. In: Bergey's Manual of Systematic Bacteriology $2^{\text {nd }}$ Edition, Springer-Verlag, New York, pp. 1399.

[4] Ludwig, W., Schleifer, K.H., Whitman, W.B. (2009) Revised road map to the phylum Firmicutes. In: De Vos, P., Garrity, G.M., Jones, D., Krieg, N.R., Ludwig, W., Rainey, F.A., Schleifer, K.H., Whitman W.B. (Eds.) Bergey's Manual of Systematic Bacteriology 3, $2^{\text {nd }}$ ed., Springer-Verlag, New York, pp. 1-17. 
[5] Winslow, C.E., Broadhurst, J., Buchanan, R.E., Krumwiede, C., Rogers, L.A., Smith, G.H. (1920) The families and genera of the bacteria: final report of the Committee of the Society of American Bacteriologists on Characterization and Classification of Bacterial Types. J. Bacteriol. 5, 191-229.

[6] Parte, A.C. (2018) LPSN - List of Prokaryotic names with Standing in Nomenclature (bacterio.net), 20 years on. Int. J. Syst. Evol. Microbiol. 68, 1825-1829.

[7] Janda, J.M., Abbott, S.L. (2007) 16S rRNA gene sequencing for bacterial identification in the diagnostic alboratory: pluses, perils and pitfalls. J. Clin. Microbiol. 45, 2761-2764.

[8] Větrovský, T., Baldrian, P. (2013) The variability of the 16S rRNA gene in bacterial genomes and its consequence for bacterial community analyses. PLoS One 8, e57923.

[9] MacLean, D., Jones, J.D., Studholme, D.J. (2009) Application of next-generation sequencing technologies to microbial genetics. Nat. Rev. Microbiol. 7, 287-296.

[10] Delsuc, F., Brinkmann, H., Philippe, H. (2005) Phylogenomics and the reconstruction of the tree of life. Nat. Rev. Microbiol. 6, 361-375.

[11] Jolley, K.A., Bliss, D.M., Bennett, J.S., Bratcher, H.B., Brehony, C., Colles, C.M., Wimalarathna, H., Harrison, O.B., Sheppard, S.K., Cody, A.J., Maiden, M.C.J. (2012) Ribosomal multilocus sequence typing: universal characterization of bacteria from domain to strain. Microbiology 158, 1005-1015.

[12] Konstantinidis, K.T., Tiedje, J.M. (2005) Towards a genome-based taxonomy for prokaryotes. J. Bacteriol. 187, 6258-6264.

[13] Goris, J., Konstantinidis, K.T., Klappenbach, J.A., Coenye, T., Vandamme, P., Tiedje, J.M. (2007) DNA-DNA hybridization values and their relationship to whole-genome sequence similarities., Int. J. Syst. Evol. Microbiol. 57, 81-91.

[14] Meier-Kolthoff, J.P., Auch, A.F., Klenk, H.-P., Göker, M. (2013) Genome sequence-based species delimitation with confidence intervals and improved distance functions. BMC Bioinformatics 14, 1-14.

[15] Konstantinidis, K.T., Tiedje, J.M. (2005) Genomic insights that advance the species definition for prokaryotes. Proc. Natl. Acad. Sci. U.S.A. 102, 2567-2572.

[16] Qin, Q.-L., Xie, B.-B., Zhang, X.-Y., Chen, X.-L., Zhou, B.-C., Zhou, J., Oren, A., Zhang, Y.-Z. (2014) A proposed genus boundary for the prokaryotes based on genomic insights. J. Bacteriol. 196, 2210-2215.

[17] NCBI Resource Coordinators (2017) Database resources of the National Center for Biotechnology Information. Nucleic Acids Res. 45, D12-D17. 
[18] Stackebrandt, E., Goebel, G.M. (1994) Taxonomic note: a place for DNA-DNA reassociation and $16 \mathrm{~S}$ rRNA sequence analysis in the present species definition in bacteriology. Int. J. Syst. Bacteriol. 44, 846-849.

[19] Besemer, J., Lomsadze, A., Borodovsky, M. (2001) GenemarkS: a self-training method for prediction of gene starts in microbial genomes. Implications for finding sequence motifs in regulatory regions. Nucleic Acids Res. 29, 2607-2618.

[20] Emms, D.M., Kelly, S. (2015) OrthoFinder: solving fundamental biases in whole genome comparisons dramatically improves orthogroup inference accuracy. Genome Biol. 16, 157.

[21] Jauffrit, F., Penel, S., Delmotte, S., Rey, C., de Vienne, D.M., Gouy, M., Charrier, J.P., Flandrois, J.P., Brochier-Armanet, C. (2016) RiboDB Database: A Comprehensive Resource for Prokaryotic Systematics. Mol. Biol. Evol. 33, 2170-2172.

[22] Hall, T.A. (1999) Bioedit: a user-friendly biological sequence alignment editor and analysis program for Windows 95/98/NT. Nucleic Acids Symp. Ser. 41, 95-98.

[23] Lee, I., Kim, Y.O., Park, S.C., Chun, J. (2015) OrthoANI: an improved algorithm and software for calculating average nucleotide identity. Int. J. Syst. Evol. Microbiol. 66, 11001103.

[24] Rodriguez-R, L.M., Konstantinidis, K.T. (2016) The enveomics collection: a toolbox for specialized analyses of microbial genomes and metagenomes. PeerJ Preprints, 4: e1900v1.

[25] Richter, M., Rosselló-Móra, R. (2009) Shifting the genomic gold standard for the prokaryotic definition. Proc. Natl. Acad. Sci. U.S.A. 106, 19126-19131.

[26] Wallace, I.M., O'Sullivan, O., Higgins, D.G., Notredame, C. (2006) M-Coffee: combining multiple sequence alignment methods with T-coffee. Nucleic Acids Res. 34, 1692-1699.

[27] Talavera, G., Castresana, J. (2007) Improvement of phylogenies after removing divergent and ambiguously aligned blocks from protein sequence alignments. Syst. Biol. 56, 564-577.

[28] Guindon, S., Dufayard, J.F., Lefort, V., Anisimova, M., Hordijk, W., Gascuel, O. (2010) New algorithms and methods to estimate maximum-likelihood phylogenies: assessing the performance of PhyML 3.0. Syst. Biol. 59, 307-321.

[29] Lefort, V., Longueville, J.-E., Gascuel, O. (2017) SMS: Smart Model Selection in PhyML. Mol. Biol. Evol. 34, 2422-2424.

[30] Anisimova, M., Gil, M., Dufayard, J.F., Dessimoz, C., Gascuel, O. (2011) Survey of branch support methods demonstrates accuracy, power, and robustness of faste likelihoodbased approximation schemes. Syst. Biol. 60, 685-699.

[31] Felsenstein, J. (1989) PHYLIP - Phylogeny Inference Package (Version 3.2). Cladistics $5,164-166$. 
[32] Nye, T.M.W., Liò, P., Gilks, W.R. (2006) A novel algorithm and web-based tool for comparing two alternative phylogenetic trees. Bioinformatics 22, 117-119.

[33] Philippe, H., Lopez, P. (2001) On the conservation of protein sequences in evolution. Trends Biochem. Sci. 26, 414-416.

[34] Li, W.-J., Zhi, X.-Y., Euzéby, J.P. (2006) Proposal of Yaniellaceae fam. nov., Yaniella gen. nov. and Sinobaca gen. nov. as replacements for the illegitimate prokaryotic name Yaniaceae Li et al. 2005, Yania Li et al. 2004 emend Li et al. 2005, and Sinococcus Li et al. 2006, respectively. Int. J. Syst. Evol. Microbiol. 58, 525-527.

[35] Seiler, H., Wenning, M., Scherer, S. (2013) Domibacillus robiginosus gen. nov., sp. nov., isolated from a pharmaceutical clean room. Int. J. Syst. Evol. Microbiol. 63, 2054-2061.

[36] de Vos, P., Ludwig, W., Schleifer, K.H., Whitman, W.B. (2009) Family IV. Paenibacillaceae fam. nov. In: De Vos, P., Garrity, G.M., Jones, D., Krieg, N.R., Ludwig, W., Rainey, F.A., Schleifer, K.H., Whitman, W.B. (Eds.) Bergey's Manual of Systematic Bacteriology 3, $2^{\text {nd }}$ ed., Springer-Verlag, New York, pp. 269-327.

[37] Garrity, G.M., Bell, J.A., Lilburn, T.G. (2005) The revised roadmap to the manual. In: Brenner, D.J., Krieg, N.R., Staley, J.T., Garrity, G.M. (Eds.) Bergey's Manual of Systematic Bacteriology $2^{\text {nd }}$ Edition Volume 2: The Proteobacteria Part B, The Gammaproteobacteria., Springer, New York, pp. 159-206.

[38] Zhang, W., Lu, Z. (2015) Phylogenomic evaluation of members above the species level within the phylum Firmicutes based on conserved proteins. Environ. Microbiol. Rep. 7, 273281.

[39] Bergey, D.H., Harrison, F.C., Breed, R.S., Hammer, B.W., Huntoon, F.W. (1923) Bergey's Manual of Determinative Bacteriology: a key for the identification of organisms of the class Schizomyces. Williams \& Wilkins, Baltimore, USA. 
Table 1

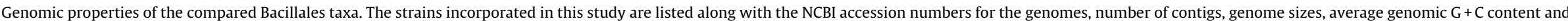

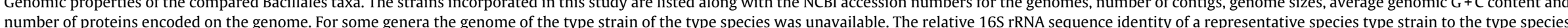
type strain for that genus is shown. Only those strains with $16 \mathrm{~S}$ rRNA gene sequence identities $>95 \%$ were selected for incorporation in the analyses.

\begin{tabular}{|c|c|c|c|c|c|c|c|}
\hline Family & Strain & NCBI Acc. \# & Contigs & $\begin{array}{l}\text { Genome } \\
\text { size }(\mathrm{Mb})\end{array}$ & $\begin{array}{l}\mathrm{G}+\mathrm{C} \\
\text { content }(\%)\end{array}$ & $\begin{array}{l}\text { \# proteins } \\
\text { encoded }\end{array}$ & $\begin{array}{l}\text { Genus type strain (\% } 16 \mathrm{~S} \text { rRNA } \\
\text { identity to type species) }\end{array}$ \\
\hline \multirow[t]{6}{*}{$\begin{array}{l}\text { Lactobacillales } \\
\text { [ORDER] }\end{array}$} & $\begin{array}{l}\text { Enterococcus faecalis DSM } \\
20478^{\mathrm{T}}\end{array}$ & ASDA01000000 & 11 & 2.88 & 37.64 & 2783 & Y \\
\hline & $\begin{array}{l}\text { Carnobacterium divergens } \\
\text { DSM } 20623^{\mathrm{T}}\end{array}$ & JQLO01000000 & Complete (1) & 2.62 & 35.10 & 2436 & $\mathrm{Y}$ \\
\hline & $\begin{array}{l}\text { Streptococcus pyogenes } \\
\text { DSM } 20565^{\mathrm{T}}\end{array}$ & LN831034 & Complete (1) & 1.91 & 38.50 & 1894 & $\mathrm{Y}$ \\
\hline & $\begin{array}{l}\text { Aerococcus viridans DSM } \\
20340^{\mathrm{T}}\end{array}$ & СР014164 & Complete (1) & 2.20 & 39.38 & 2018 & $\mathrm{Y}$ \\
\hline & $\begin{array}{l}\text { Lactobacillus delbrueckii } \\
\text { DSM } 20074^{\mathrm{T}}\end{array}$ & СР018615 & Complete (1) & 1.95 & 49.63 & 2055 & $\mathrm{Y}$ \\
\hline & $\begin{array}{l}\text { Leuconostoc mesenteroides } \\
\text { DSM } 20343^{\mathrm{T}}\end{array}$ & СР000414 & Complete (2) & 2.08 & 37.67 & 2012 & $\mathrm{Y}$ \\
\hline \multirow[t]{2}{*}{ Listeriaceae } & $\begin{array}{l}\text { L. monocytogenes DSM } \\
20600^{\mathrm{T}}\end{array}$ & LT906436 & Complete (1) & 2.86 & 38.06 & 2796 & $\mathrm{Y}$ \\
\hline & $\begin{array}{l}\text { B. thermosphacta DSM } \\
20171^{\mathrm{T}}\end{array}$ & JHZM01000000 & 33 & 2.50 & 36.33 & 2412 & $\mathrm{Y}$ \\
\hline \multirow[t]{5}{*}{ Staphylococcaceae } & $\begin{array}{l}\text { G. haemolysans ATCC } \\
10379^{\mathrm{T}}\end{array}$ & ACDZ01000000 & 15 & 1.92 & 30.88 & 1691 & Y \\
\hline & S. aureus DSM $20231^{\mathrm{T}}$ & СР011526 & Complete (2) & 2.78 & 32.84 & 2509 & $\mathrm{Y}$ \\
\hline & A. persicus DSM $28306^{\mathrm{T}}$ & FOIT01000000 & 8 & 2.05 & 38.48 & 2024 & $\mathrm{Y}$ \\
\hline & S. luteus DSM $17002^{\mathrm{T}}$ & JONV01000000 & 13 & 2.55 & 49.17 & 2612 & 96.3\% (S. roseus DSM 5351 ${ }^{\mathrm{T}}$ ) \\
\hline & $\begin{array}{l}\text { J. psychrophilus DSM } \\
19085^{\mathrm{T}}\end{array}$ & AUEF01000000 & 33 & 2.34 & 40.24 & 2396 & $98.3 \%$ (J. halotolerans JCM $11198^{\mathrm{T}}$ ) \\
\hline \multirow[t]{14}{*}{ Planococcaceae } & $\begin{array}{l}\text { Bhargavaea cecembensis } \\
\text { DSM } 22132^{\mathrm{T}}\end{array}$ & AOFT01000000 & 39 & 3.21 & 54.83 & 3263 & Y \\
\hline & $\begin{array}{l}\text { Sporosarcina ureae DSM } \\
2281^{\mathrm{T}}\end{array}$ & AUDQ01000000 & 36 & 3.32 & 41.41 & 3265 & 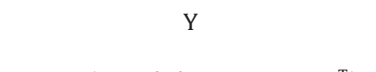 \\
\hline & R. pycnus DSM $15030^{\mathrm{T}}$ & NJAS01000000 & 2 & 3.85 & 34.65 & 3585 & 97.7\% (R. stabeksii DSM $25578^{\mathrm{T}}$ ) \\
\hline & K. zopfii DSM $20580^{\mathrm{T}}$ & QFVS01000000 & 110 & 2.88 & 37.05 & 2893 & $\mathrm{Y}$ \\
\hline & V. arvi DSM $16317^{\mathrm{T}}$ & LILB01000000 & 19 & 4.70 & 35.36 & 4495 & $\mathrm{Y}$ \\
\hline & S. silvestris DSM $12223^{\mathrm{T}}$ & СР014609 & Complete (1) & 3.99 & 38.60 & 3831 & $\mathrm{Y}$ \\
\hline & C. latum DSM $14151^{\mathrm{T}}$ & MATO01000000 & 97 & 3.59 & 42.70 & 3256 & $\mathrm{Y}$ \\
\hline & $\begin{array}{l}\text { L. boronitolerans DSM } \\
17140^{\mathrm{T}}\end{array}$ & JPVR01000000 & 81 & 4.56 & 37.56 & 4524 & Y \\
\hline & $\begin{array}{l}\text { Psychrobacillus insolitus } \\
\text { DSM } 5^{\mathrm{T}}\end{array}$ & QKZI01000000 & 33 & 3.29 & 36.02 & 3230 & $\mathrm{Y}$ \\
\hline & $\begin{array}{l}\text { Paenisporosarcina } \\
\text { quisquiliarum JCM } 14041^{\mathrm{T}}\end{array}$ & FOBQ01000000 & 20 & 4.03 & 35.96 & 3893 & 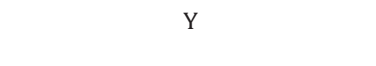 \\
\hline & $\begin{array}{l}\text { Planococcus rifietoensis } \\
\text { DSM } 15069^{\mathrm{T}}\end{array}$ & СР013659 & Complete (1) & 3.51 & 48.45 & 3550 & 99.0\% (P. citreus DSM $20549^{\mathrm{T}}$ ) \\
\hline & $\begin{array}{l}\text { Planomicrobium glaciei } \\
\text { DSM } 24857^{\mathrm{T}}\end{array}$ & FNDC01000000 & 33 & 3.92 & 46.74 & 3946 & 97.4\% (P. koreense JCM $10704^{\mathrm{T}}$ ) \\
\hline & J. alimentarius DSM $18867^{\mathrm{T}}$ & JXRQ01000000 & 32 & 3.36 & 43.13 & 3514 & $\mathrm{Y}$ \\
\hline & D. robiginosus DSM $25058^{\mathrm{T}}$ & LAHL01000000 & 106 & 4.69 & 42.73 & 4771 & $\mathrm{Y}$ \\
\hline
\end{tabular}


Table 1 (Continued)

\begin{tabular}{|c|c|c|c|c|c|c|c|}
\hline Family & Strain & NCBI Acc. \# & Contigs & $\begin{array}{l}\text { Genome } \\
\text { size }(\mathrm{Mb})\end{array}$ & $\begin{array}{l}\mathrm{G}+\mathrm{C} \\
\text { content }(\%)\end{array}$ & $\begin{array}{l}\text { \# proteins } \\
\text { encoded }\end{array}$ & $\begin{array}{l}\text { Genus type strain (\% } 16 \mathrm{~S} \text { rRNA } \\
\text { identity to type species) }\end{array}$ \\
\hline \multirow[t]{6}{*}{ Bacillaceae 1} & $\begin{array}{l}\text { Caldibacillus debilis DSM } \\
16016^{\mathrm{T}}\end{array}$ & ARVR01000000 & 42 & 3.06 & 51.63 & 3223 & Y \\
\hline & $\begin{array}{l}\text { Anoxybacillus } \\
\text { pushchinoensis DSM } \\
12423^{\mathrm{T}}\end{array}$ & FOJQ01000000 & 117 & 2.62 & 42.06 & 2792 & Y \\
\hline & $\begin{array}{l}\text { Geobacillus } \\
\text { stearothermophilus DSM } \\
22^{\mathrm{T}}\end{array}$ & JYNWQ01000000 & 106 & 2.63 & 53.07 & 2969 & Y \\
\hline & $\begin{array}{l}\text { Parageobacillus } \\
\text { thermoglucosidasius DSM } \\
2542^{\mathrm{T}}\end{array}$ & СР012712 & Complete (1) & 3.87 & 43.89 & 3923 & Y \\
\hline & $\begin{array}{l}\text { Aeribacillus pallidus DSM } \\
3670^{\mathrm{T}}\end{array}$ & СР017703 & Complete (1) & 4.09 & 39.32 & 4062 & $\mathrm{Y}$ \\
\hline & B. subtilis DSM $10^{\mathrm{T}}$ & СР011115 & Complete (1) & 4.22 & 43.51 & 4231 & Y \\
\hline \multirow[t]{19}{*}{ Bacillaceae 2} & $\begin{array}{l}\text { Pelagirhabdus alkalitolerans } \\
\text { KCTC } 33632^{\mathrm{T}}\end{array}$ & КСТС 33632 & 23 & 2.53 & 37.08 & 2390 & $\mathrm{Y}$ \\
\hline & $\begin{array}{l}\text { Streptohalobacillus salinus } \\
\text { DSM } 22440^{\mathrm{T}}\end{array}$ & QJJR01000000 & 37 & 2.53 & 39.38 & 2319 & $\mathrm{Y}$ \\
\hline & $\begin{array}{l}\text { Halolactibacillus halophilus } \\
\text { DSM } 17073^{\mathrm{T}}\end{array}$ & FMYI01000000 & 95 & 2.70 & 38.44 & 2630 & $\mathrm{Y}$ \\
\hline & $\begin{array}{l}\text { Amphibacillus xylanus DSM } \\
6626^{\mathrm{T}}\end{array}$ & АР012050 & Complete (1) & 2.57 & 35.72 & 2356 & $\mathrm{Y}$ \\
\hline & $\begin{array}{l}\text { Gracilibacillus kekensis DSM } \\
23178^{\mathrm{T}}\end{array}$ & FRCZ01000000 & 17 & 3.98 & 36.00 & 3730 & $96.0 \%\left(\right.$ G. halotolerans DSM $11805^{\mathrm{T}}$ ) \\
\hline & $\begin{array}{l}\text { Sediminibacillus halophilus } \\
\text { DSM } 18088^{\mathrm{T}}\end{array}$ & FHNF01000000 & 13 & 4.15 & 42.86 & 4137 & Y \\
\hline & $\begin{array}{l}\text { Lentibacillus halodurans } \\
\text { DSM } 18342^{\mathrm{T}}\end{array}$ & FOJW01000000 & 31 & 3.67 & 41.57 & 3651 & 95.7\% (L. salicampi JCM $11462^{\mathrm{T}}$ ) \\
\hline & $\begin{array}{l}\text { Virgibacillus pantothenticus } \\
\text { DSM } 26^{\mathrm{T}}\end{array}$ & LGTO01000000 & 16 & 4.74 & 37.22 & 4343 & Y \\
\hline & $\begin{array}{l}\text { Oceanobacillus iheyensis } \\
\text { DSM } 14371^{\mathrm{T}}\end{array}$ & BA000028 & Complete (1) & 3.63 & 35.68 & 3503 & Y \\
\hline & $\begin{array}{l}\text { Paucisalibacillus globulus } \\
\text { DSM } 18846^{\mathrm{T}}\end{array}$ & AXVK01000000 & 50 & 4.23 & 35.79 & 4117 & 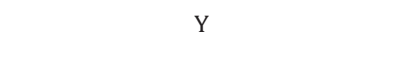 \\
\hline & $\begin{array}{l}\text { Ornithinibacillus } \\
\text { californiensis DSM } 16627^{\mathrm{T}}\end{array}$ & LDUE01000000 & 70 & 3.98 & 36.96 & 3993 & $97.2 \%\left(\right.$ O. bavariensis DSM $\left.15681^{\mathrm{T}}\right)$ \\
\hline & $\begin{array}{l}\text { Pontibacillus chungwhensis } \\
\text { DSM } 16287^{\mathrm{T}}\end{array}$ & AVBG01000000 & 40 & 3.87 & 40.77 & 3846 & 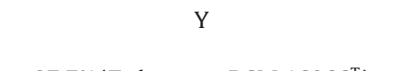 \\
\hline & $\begin{array}{l}\text { Thalassobacillus cyri DSM } \\
21635^{\mathrm{T}}\end{array}$ & FNQR01000000 & 37 & 4.30 & 42.49 & 4355 & $97.7 \%\left(\right.$ T. devorans DSM $16966^{\mathrm{T}}$ ) \\
\hline & $\begin{array}{l}\text { Halobacillus halophilus DSM } \\
2266^{\mathrm{T}}\end{array}$ & HE717023 & Complete (3) & 4.17 & 41.82 & 4137 & $\mathrm{Y}$ \\
\hline & $\begin{array}{l}\text { Salimicrobium album DSM } \\
20748^{\mathrm{T}}\end{array}$ & FNOS01000000 & 13 & 2.63 & 46.89 & 2693 & $\mathrm{Y}$ \\
\hline & $\begin{array}{l}\text { Tenuibacillus multivorans } \\
\text { NBRC } 100370^{\mathrm{T}}\end{array}$ & FNIG01000000 & 18 & 2.95 & 37.69 & 3046 & 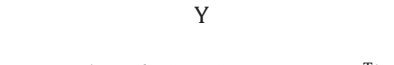 \\
\hline & $\begin{array}{l}\text { Piscibacillus halophilus DSM } \\
21633^{\mathrm{T}}\end{array}$ & FOES01000000 & 83 & 2.99 & 36.74 & 3106 & 98.3\% (P. salipiscarius JCM $13188^{\mathrm{T}}$ ) \\
\hline & $\begin{array}{l}\text { Halalkalibacillus halophilus } \\
\text { DSM } 18494^{\mathrm{T}}\end{array}$ & AUHI01000000 & 27 & 2.71 & 37.43 & 2749 & $\mathrm{Y}$ \\
\hline & $\begin{array}{l}\text { Salinibacillus kushneri JCM } \\
12390^{\mathrm{T}}\end{array}$ & FOHJ01000000 & 23 & 3.49 & 37.40 & 3525 & 97.6\% (S. aidingensis JCM $12389^{\mathrm{T}}$ ) \\
\hline
\end{tabular}


Table 1 (Continued)

\begin{tabular}{|c|c|c|c|c|c|c|c|}
\hline Family & Strain & NCBI Acc. \# & Contigs & $\begin{array}{l}\text { Genome } \\
\text { size }(\mathrm{Mb})\end{array}$ & $\begin{array}{l}\mathrm{G}+\mathrm{C} \\
\text { content }(\%)\end{array}$ & $\begin{array}{l}\text { \# proteins } \\
\text { encoded }\end{array}$ & $\begin{array}{l}\text { Genus type strain (\% } 16 \mathrm{~S} \text { rRNA } \\
\text { identity to type species) }\end{array}$ \\
\hline & $\begin{array}{l}\text { Terribacillus saccharophilus } \\
\text { DSM } 21619^{\mathrm{T}}\end{array}$ & FOCD01000000 & 13 & 3.63 & 42.53 & 3693 & $\mathrm{Y}$ \\
\hline \multirow[t]{2}{*}{ Sporolactobacillaceae } & $\begin{array}{l}\text { Tuberibacillus calidus DSM } \\
17572^{\mathrm{T}}\end{array}$ & AUMM01000000 & 90 & 3.23 & 44.00 & 3272 & $\mathrm{Y}$ \\
\hline & $\begin{array}{l}\text { Sporolactobacillus } \\
\text { laevolacticus DSM } 442^{\mathrm{T}}\end{array}$ & AWTC01000000 & 32 & 3.59 & 42.72 & 3556 & $97.2 \%$ (S. inulinus DSM $20348^{\mathrm{T}}$ ) \\
\hline $\begin{array}{l}\text { Family incertae } \\
\text { sedis XII }\end{array}$ & $\begin{array}{l}\text { Exiguobacterium } \\
\text { aurantiacum DSM } 6208^{\mathrm{T}}\end{array}$ & JNIQ01000000 & 2 & 3.04 & 52.79 & 3120 & Y \\
\hline \multirow[t]{8}{*}{ Bacillaceae 3} & $\begin{array}{l}\text { Natribacillus halophilus } \\
\text { DSM } 21771^{\mathrm{T}}\end{array}$ & FNEN01000000 & 47 & 3.30 & 46.80 & 3487 & Y \\
\hline & $\begin{array}{l}\text { Salsuginibacillus kocurii } \\
\text { DSM } 18087^{\mathrm{T}}\end{array}$ & ARIV01000000 & 26 & 3.83 & 43.16 & 3689 & $\mathrm{Y}$ \\
\hline & S. qinghaiensis DSM $17008^{\mathrm{T}}$ & $2636416020^{\mathrm{a}}$ & 14 & 3.40 & 44.71 & 3449 & $\mathrm{Y}$ \\
\hline & $\begin{array}{l}\text { Alteribacillus bidgolensis } \\
\text { DSM } 25260^{\mathrm{T}}\end{array}$ & NJAU01000000 & 3 & 4.70 & 38.90 & 4705 & Y \\
\hline & $\begin{array}{l}\text { Marinococcus halophilus } \\
\text { DSM } 20408^{\mathrm{T}}\end{array}$ & NPFA01000000 & 64 & 3.26 & 47.25 & 3406 & $\mathrm{Y}$ \\
\hline & $\begin{array}{l}\text { Salipaludibacillus } \\
\text { aurantiacus DSM } 18675^{\mathrm{T}}\end{array}$ & AUCJ01000000 & 15 & 4.02 & 42.46 & 3961 & Y \\
\hline & $\begin{array}{l}\text { Salisediminibacterium } \\
\text { halotolerans DSM } 21619^{\mathrm{T}}\end{array}$ & $2684623023^{a}$ & 20 & 2.84 & 46.87 & 2774 & Y \\
\hline & $\begin{array}{l}\text { Anaerobacillus } \\
\text { arseniciselenatis DSM } \\
15340^{\mathrm{T}}\end{array}$ & MLQQ01000000 & 58 & 3.95 & 36.09 & 3735 & Y \\
\hline \multirow[t]{2}{*}{ Paenibacillaceae 2} & A. migulanus DSM $2895^{\mathrm{T}}$ & LGUG01000000 & 28 & 6.33 & 43.06 & 6496 & 99.4\% (A. aneurinilyticus DSM $5562^{\mathrm{T}}$ ) \\
\hline & $\begin{array}{l}\text { Brevibacillus brevis DSM } \\
30^{\mathrm{T}}\end{array}$ & PXXZ01000000 & 97 & 6.61 & 47.38 & 6482 & $\mathrm{Y}$ \\
\hline $\begin{array}{l}\text { Family incertae } \\
\text { sedis } \mathrm{X}\end{array}$ & $\begin{array}{l}\text { Thermicanus aegyptius DSM } \\
12793^{\mathrm{T}}\end{array}$ & AZNU01000000 & 11 & 3.66 & 48.21 & 3678 & Y \\
\hline \multirow[t]{5}{*}{ Thermoactinomycetaceae } & $\begin{array}{l}\text { Novibacillus thermophilus } \\
\text { KCTC } 33118^{\mathrm{T}}\end{array}$ & СР019699 & Complete (1) & 3.63 & 50.44 & 3635 & Y \\
\hline & $\begin{array}{l}\text { Thermoflavimicrobium } \\
\text { dichotomicum DSM } 44778^{\mathrm{T}}\end{array}$ & FORR01000000 & 77 & 3.85 & 42.53 & 3710 & Y \\
\hline & $\begin{array}{l}\text { Lihuaxuella thermophila } \\
\text { DSM } 4670^{\mathrm{T}}\end{array}$ & FOCQ01000000 & 40 & 3.81 & 48.96 & 3830 & Y \\
\hline & $\begin{array}{l}\text { Laceyella sediminis DSM } \\
45262^{\mathrm{T}}\end{array}$ & PVTZ01000000 & 44 & 3.39 & 48.89 & 3432 & $99.6 \%\left(\right.$ L. sacchari DSM $43356^{\mathrm{T}}$ ) \\
\hline & $\begin{array}{l}\text { Thermoactinomyces vulgaris } \\
\text { DSM } 43016^{\mathrm{T}}\end{array}$ & $2616644978^{a}$ & 15 & 2.56 & 47.94 & 2731 & Y \\
\hline
\end{tabular}


Table 1 (Continued)

\begin{tabular}{|c|c|c|c|c|c|c|c|}
\hline Family & Strain & NCBI Acc. \# & Contigs & $\begin{array}{l}\text { Genome } \\
\text { size }(\mathrm{Mb})\end{array}$ & $\begin{array}{l}\mathrm{G}+\mathrm{C} \\
\text { content }(\%)\end{array}$ & $\begin{array}{l}\text { \# proteins } \\
\text { encoded }\end{array}$ & $\begin{array}{l}\text { Genus type strain (\% } 16 \mathrm{~S} \text { rRNA } \\
\text { identity to type species) }\end{array}$ \\
\hline & $\begin{array}{l}\text { Risungbinella massiliensis } \\
\text { DSM } 44691^{\mathrm{T}}\end{array}$ & CECI01000000 & 9 & 3.42 & 40.25 & 3405 & 98.0\% (R. pyongyangensis NRRL B-59118 $)$ \\
\hline & $\begin{array}{l}\text { Shimazuella kribbensis DSM } \\
45090^{\mathrm{T}}\end{array}$ & ATZF01000000 & 46 & 4.18 & 38.37 & 4272 & $\mathrm{Y}$ \\
\hline & $\begin{array}{l}\text { Seinonella peptonophila } \\
\text { DSM } 44666^{\mathrm{T}}\end{array}$ & FQVL01000000 & 41 & 3.84 & 39.16 & 3759 & Y \\
\hline & $\begin{array}{l}\text { Planifilum fimeticola DSM } \\
44946^{\mathrm{T}}\end{array}$ & PVNE01000000 & 73 & 3.59 & 57.50 & 3684 & 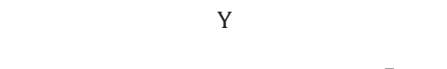 \\
\hline & $\begin{array}{l}\text { Melghirimyces } \\
\text { thermohalophilus DSM } \\
45514^{\mathrm{T}}\end{array}$ & FMZA01000000 & 35 & 3.19 & 52.91 & 3343 & 96.3\% (M. algeriensis DSM 45474 ${ }^{\mathrm{T}}$ ) \\
\hline & $\begin{array}{l}\text { Kroppenstedtia eburnea } \\
\text { DSM } 45196^{\mathrm{T}}\end{array}$ & FTOD01000000 & 27 & 3.53 & 54.09 & 3566 & Y \\
\hline & $\begin{array}{l}\text { Desmospora activa DSM } \\
45169^{\mathrm{T}}\end{array}$ & PZZP01000000 & 16 & 3.79 & 49.21 & 3715 & Y \\
\hline & $\begin{array}{l}\text { Marininema mesophilum } \\
\text { DSM } 45610^{\mathrm{T}}\end{array}$ & FNNQ01000000 & 42 & 3.33 & 44.80 & 3125 & $\mathrm{Y}$ \\
\hline \multirow[t]{2}{*}{ Bacillaceae 4} & $\begin{array}{l}\text { T. decaturensis DSM } \\
103037^{\mathrm{T}}\end{array}$ & LSKU01000000 & 3 & 2.78 & 36.09 & 2881 & $95.8 \%\left(\right.$ T. fermentans DSM $23802^{\mathrm{T}}$ ) \\
\hline & $\begin{array}{l}\text { V. modesticaldus DSM } \\
14931^{\mathrm{T}}\end{array}$ & MIJF01000000 & 100 & 2.22 & 33.61 & 2240 & Y \\
\hline \multirow[t]{5}{*}{ Paenibacillaceae 1} & $\begin{array}{l}\text { C. thermotolerans DSM } \\
17683^{\mathrm{T}}\end{array}$ & AUCP01000000 & 156 & 5.04 & 58.30 & 4944 & ( \\
\hline & T. composti DSM $18247^{\mathrm{T}}$ & СР003255 & Complete (2) & 4.36 & 60.12 & 4245 & 97.4\% (T. xylanilyticus CNCM I-1017T) \\
\hline & P. polymyхa DSM $36^{\mathrm{T}}$ & AFOX01000000 & 65 & 5.90 & 44.93 & 5430 & $\mathrm{Y}$ \\
\hline & $\begin{array}{l}\text { F. panacisegetis DSM } \\
28129^{\mathrm{T}}\end{array}$ & FNBG01000000 & 76 & 5.26 & 42.84 & 4823 & 97.0\% (F. aquaticus DSM $17643^{\mathrm{T}}$ ) \\
\hline & S. sacchari DSM $19268^{\mathrm{T}}$ & JFBU01000000 & 25 & 6.07 & 52.72 & 5443 & Y \\
\hline \multirow[t]{4}{*}{ Alicyclobacillaceae } & $\begin{array}{l}\text { Alicyclobacillus } \\
\text { acidocaldarius DSM } 446^{\mathrm{T}}\end{array}$ & СР001727 & Complete (4) & 3.21 & 61.89 & 3231 & Y \\
\hline & Kyrpidia tusciae DSM $2912^{\mathrm{T}}$ & СР002017 & Complete (1) & 3.38 & 59.11 & 3365 & $\mathrm{Y}$ \\
\hline & $\begin{array}{l}\text { Effusibacillus lacus DSM } \\
27172^{\mathrm{T}}\end{array}$ & BDUF01000000 & 127 & 3.90 & 49.68 & 4069 & Y \\
\hline & $\begin{array}{l}\text { Tumebacillus } \\
\text { permanentifrigoris DSM } \\
18773^{\mathrm{T}}\end{array}$ & QGGL01000000 & 61 & 4.69 & 54.91 & 4474 & Y \\
\hline $\begin{array}{l}\text { Family incertae } \\
\text { sedis }\end{array}$ & $\begin{array}{l}\text { D. alkaliarsenatis DSM } \\
2408^{\mathrm{T}}\end{array}$ & MJJE01000000 & 36 & 3.11 & 37.52 & 2912 & Y \\
\hline $\begin{array}{l}\text { Clostridiales } \\
\text { [ORDER] }\end{array}$ & C. butyricum DSM $10702^{\mathrm{T}}$ & AQQF01000000 & 40 & 4.60 & 28.50 & 4084 & Y \\
\hline
\end{tabular}

a Denotes those strains for which the genomes were derived from the Joint Genome Institute Integrated Microbial Genomes (JGI-IMG) database. The IMG accession numbers are indicated. 


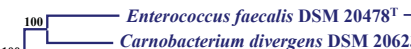

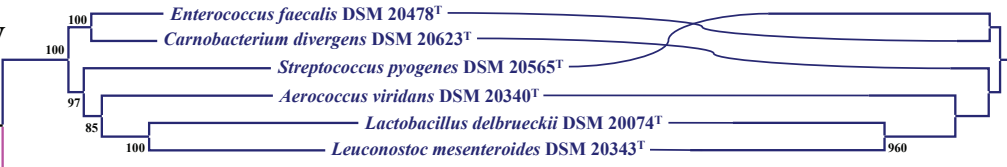

16S rRNA ML phylogeny
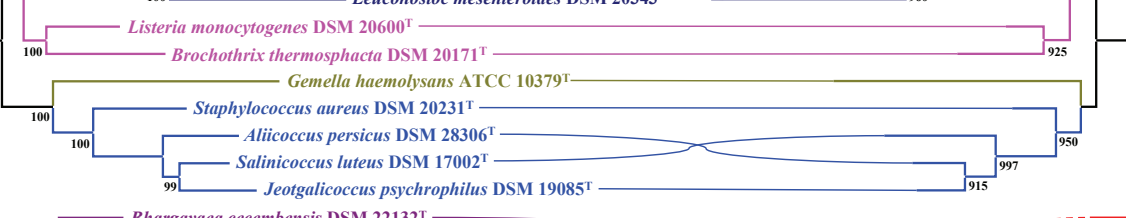

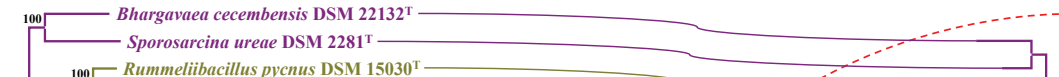

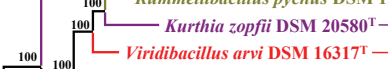

$\prod_{100}^{100}$ - Solibacillus silvestris DSM $12223^{\mathrm{T}}$

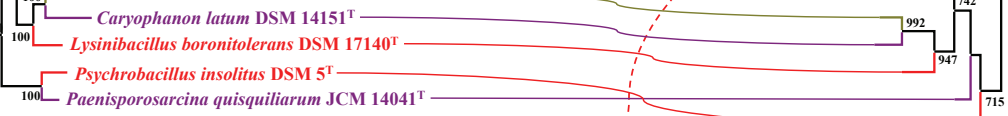

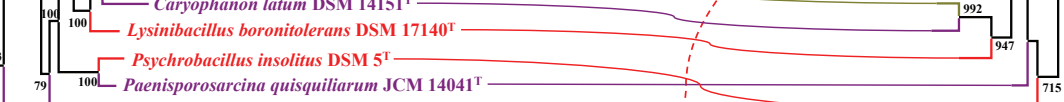

_ Planococcus rifietoensis DSM $15069^{\mathrm{T}}$

${ }_{100}$ - Planomicrobium glaciei DSM $24857^{\mathrm{T}}$

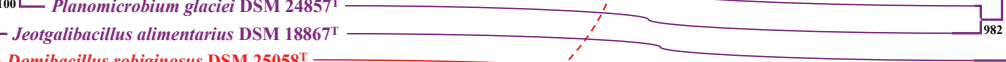

Caldibacillus debilis DSM $16016^{\mathrm{T}}$

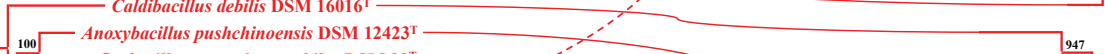

Geobacillus stearothermophilus DSM $22^{\mathrm{T}}$

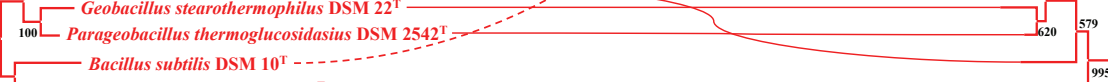

$7 6 \longdiv { 7 } -$ Pelagirhabdus alkalitolerans KCTC $33632^{\mathrm{T}}$

- Streptohalobacillus salinus DSM 22440

Halolactibacillus halophilus DSM 17

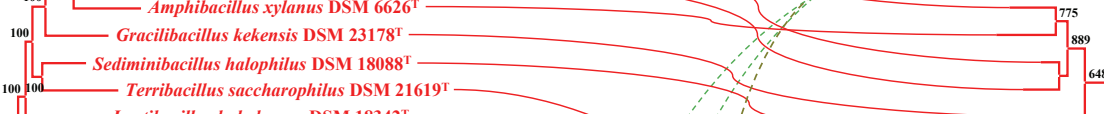

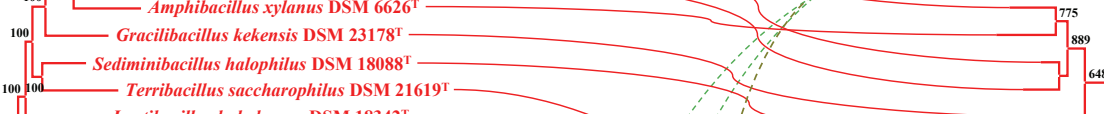

Lentibacillus halodurans DSM $18342^{\mathrm{T}}$

100 Oceanobacillus iheyensis DSM $14371^{7}$

- Paucisalibacillus globulus DSM 18846

$\sqrt{9929}$

Pontibacillus chungwhensis DSM $16287^{\mathrm{T}}$

100 Thalassobacillus cyri DSM $21635^{\mathrm{T}}$

Halobacillus halophilus DSM $2266^{\mathrm{T}}$

- Salimicrobium album DSM $20748^{\mathrm{T}}$

$100-$ Tenuibacillus multivorans NBRC 100370

— Piscibacillus halophilus DSM $21633^{\mathrm{T}}$

Halalkalibacillus halophilus DSM $18494^{\mathrm{T}}$

- Salinibacillus aidingensis JCM $12390^{\mathrm{T}}$

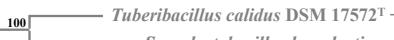

Exiguobacterium aurantiacum DSM $6208^{\mathrm{T}} \ldots$

Natribacillus halophilus DSM $21771^{\mathrm{T}}$

100 Salsuginibacillus kocurii DSM 18087

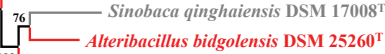

Marinococcus halophilus DSM 20408

Salipaludibacillus aurantiacus DSM $18675^{1}$

Salisediminibacterium halotolerans DSM $26530^{\mathrm{F}^{\prime}}$

Anaerobacillus arseniciselenatis DSM $15340^{\mathrm{T}}$

Aneurinibacillus migulanus DSM $2895^{\mathrm{T}}-\ldots, \ldots=$

Brevibacillus brevis DSM $30^{\mathrm{T}} \ldots \ldots \ldots$

$\stackrel{100}{\square}$ Thermobacillus compost $\mathrm{DSM} 18247^{\mathrm{T}}$

- Fontibacillus panacisegetis DSM 28129

- Paenibacillus polymyxa DSM $36^{\mathrm{T}}$

- Saccharibacillus sacchari DSM $19268^{\top}$

- Thermicanus aegyptius DSM $12793^{\mathrm{T}}$

$100 \sqrt{100} \square$ Tepidibacillus decaturensis DSM $103037^{\mathrm{T}}$

Novibacillus thermophilus KCTC $33118^{\mathrm{T}}$

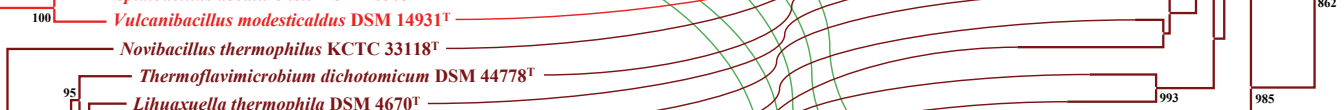

Thermoactinomyces vulgars

100 100 Thermoactinomyces vulgaris DSM $43016^{\mathrm{T}}$

- Risungbinella massiliensis DSM $44691^{\mathrm{T}}$

Shimazuella kribbensis $\mathrm{DSM} 45090^{\mathrm{T}}$
Seinonella peptonophila $\mathrm{DSM} 44666^{\mathrm{T}}$

Planifilum fimeticola DSM $44946^{\mathrm{T}}$

Melghirimyces thermohalophilus DSM $45514^{\mathrm{T}}$

Kroppenstedtia eburnea DSM $45196^{\mathrm{T}}$

${ }^{100}$

- Marininema mesophilum DSM $45610^{\mathrm{T}}$

- Alicyclobacillus acidocaldarius DSM $446^{\mathrm{T}}$

Kyrpidia tusciae DSM $2912^{\mathrm{T}}$

Effusibacillus pohliae DSM $22757^{\mathrm{T}}$

Tumebacillus permanentifrigoris DSM $18773^{\mathrm{T}}$

Desulfuribacillus alkaliarsenatis DSM $24608^{\mathrm{T}}$

Clostridium butyricum DSM $10702^{\mathrm{T}}$ 


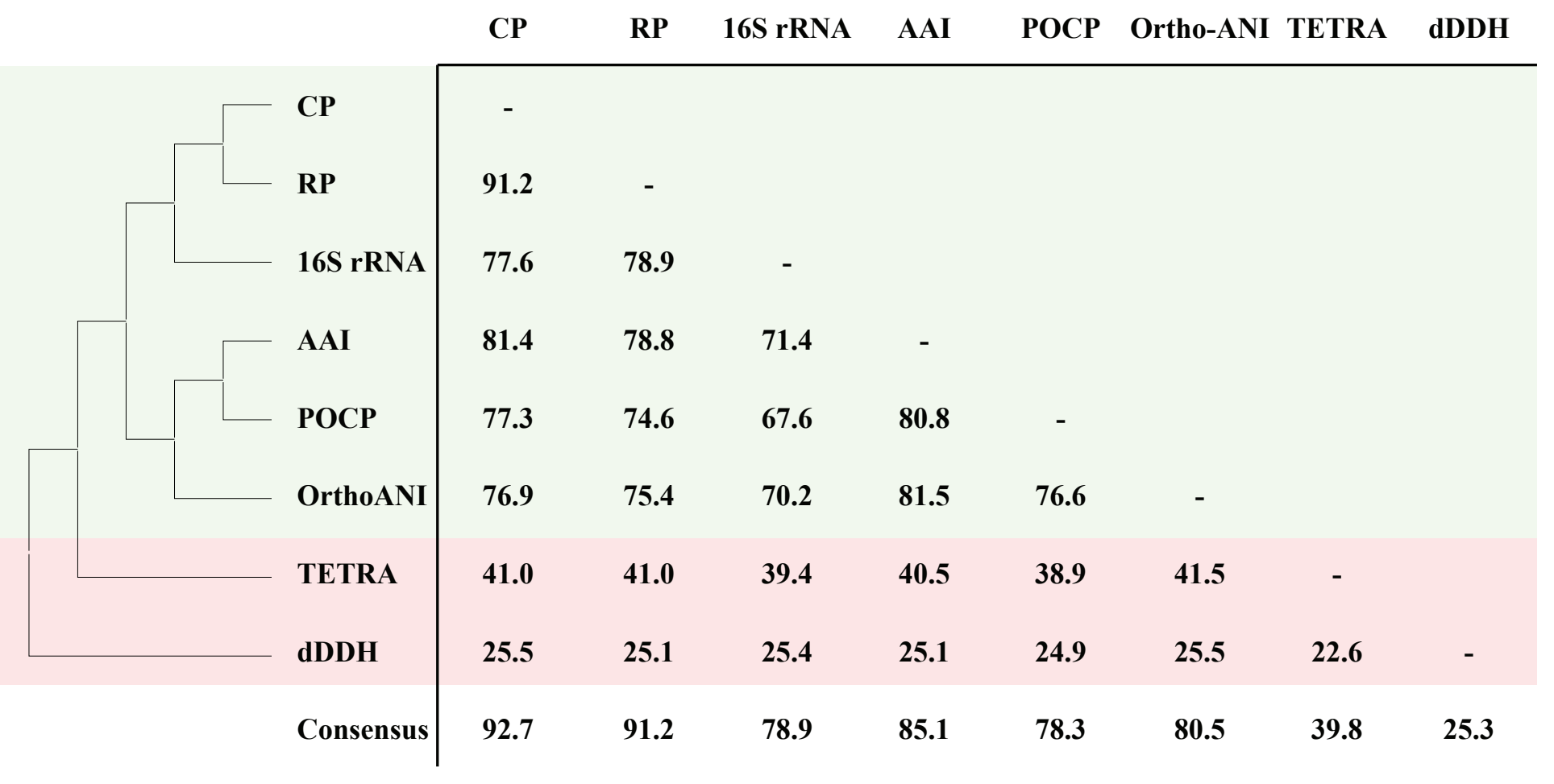

Figure 2 


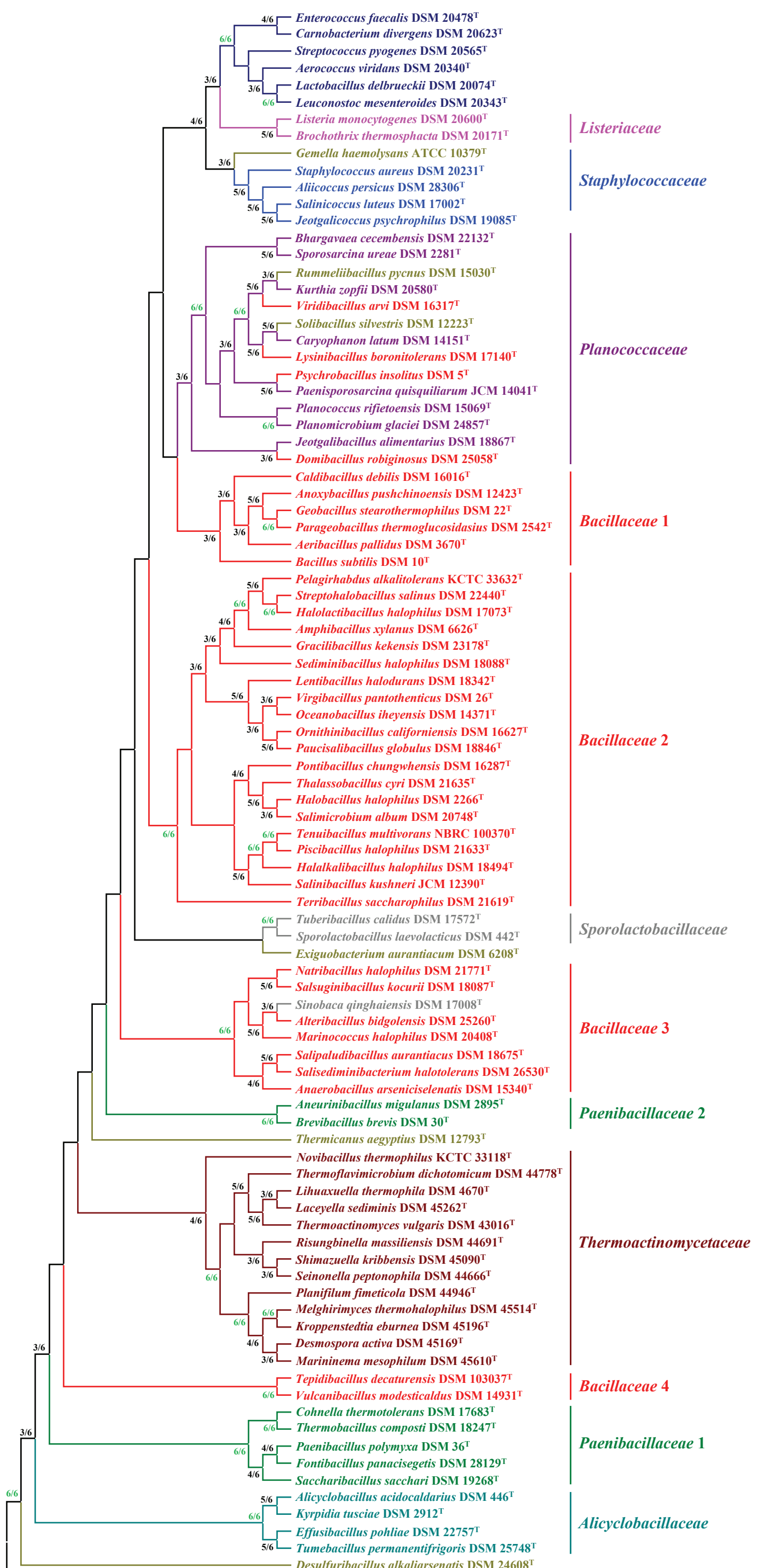

Lactobacillales 
- Gemella haemolysans ATCC 10379T

- Enterococcus faecalis DSM 20478

- Carnobacterium divergens DSM $20623^{\mathrm{T}}$

Streptococcus pyogenes DSM $20565^{\mathrm{T}}$

Aerococcus viridans DSM $20340^{\mathrm{T}}$

Lactobacillus delbrueckii DSM 20074T

Leuconostoc mesenteroides DSM $20343^{\mathrm{T}}$

Listeria monocytogenes DSM $20600^{\mathrm{T}}$
Brochothrix thermosphacta DSM $20171^{\mathrm{T}}$

- Staphylococcus aureus DSM $20231^{\mathrm{T}}$

Aliicoccus persicus DSM $28306^{\mathrm{T}}$

Salinicoccus luteus DSM $17002^{\mathrm{T}}$

Jeotgalicoccus psychrophilus DSM $19085^{\mathrm{T}}$

Exiguobacterium aurantiacum $\mathrm{DSM} 620 \mathrm{8}^{\mathrm{T}}$
Bhargavaea cecembensis DSM $22132^{\mathrm{T}}$ Sporosarcina ureae DSM $2281^{\mathrm{T}}$

- Rummeliibacillus pycnus DSM $15030^{\mathrm{T}}$

Viridibacillus arvi DSM $16317^{\mathrm{T}}$

Kurthia zopfii DSM 20580

Solibacillus silvestris DSM $12223^{\mathrm{T}}$

Lysinibacillus boronitolerans DSM $17140^{\mathrm{T}}$

- Caryophanon latum DSM 14151

Psychrobacillus insolitus DSM $5^{\mathrm{T}}$

- Paenisporosarcina quisquiliarum JCM $14041^{\mathrm{T}}$

- Planococcus rifietoensis DSM $15069^{\mathrm{T}}$

Planomicrobium glaciei DSM $24857^{\mathrm{T}}$

- Jeotgalibacillus alimentarius DSM $18867^{\mathrm{T}}$

Domibacillus robiginosus DSM $25058^{\mathrm{T}}$

Caldibacillus debilis DSM $16016^{\mathrm{T}}$

Anoxybacillus pushchinoensis DSM $12423^{\mathrm{T}}$

Geobacillus stearothermophilus DSM $22^{\mathrm{T}}$

Parageobacillus thermoglucosidasius DSM $2542^{\mathrm{T}}$

Aeribacillus pallidus DSM $3670^{\mathrm{T}}$

Bacillus subtilis DSM $10^{\mathrm{T}}$

Pelagirhabdus alkalitolerans $\mathrm{KCTC} 33632^{\mathrm{T}}$
Streptohalobacillus salinus DSM $22440^{\mathrm{T}}$
Halolactibacillus halophilus DSM $17073^{\mathrm{T}}$

- Amphibacillus xylanus DSM $6626^{\mathrm{T}}$ Gracilibacillus kekensis DSM $23178^{\mathrm{T}}$

Sediminibacillus halophilus DSM 18088

Lentibacillus halodurans DSM $18342^{\mathrm{T}}$

-Virgibacillus pantothenticus DSM $26^{\mathrm{T}}$

- Paucisalibacillus globulus DSM $18846^{\mathrm{T}}$

Ornithinibacillus californiensis DSM $16627^{\mathrm{T}}$

Oceanobacillus iheyensis DSM $14371^{\mathrm{T}}$

Pontibacillus chungwhensis DSM 16287

Thalassobacillus cyri DSM $21635^{\mathrm{T}}$

Halobacillus halophilus DSM $2266^{\mathrm{T}}$

Salimicrobium album DSM 20748

- Tenuibacillus multivorans NBRC $100370^{\mathrm{T}}$

- Piscibacillus halophilus DSM 21633T

- Halalkalibacillus halophilus DSM $18494^{\mathrm{T}}$

Salinibacillus aidingensis JCM $12390^{\mathrm{T}}$

Terribacillus saccharophilus DSM 21619 ${ }^{\mathrm{T}}$

- Natribacillus halophilus DSM 21771 ${ }^{\mathrm{T}}$

Salsuginibacillus kocurii DSM $18087^{\mathrm{T}}$

Sinobaca qinghaiensis DSM $17008^{\mathrm{T}}$

Alteribacillus bidgolensis DSM $25260^{\mathrm{T}}$

- Marinococcus halophilus DSM $20408^{\mathrm{T}}$

Salipaludibacillus aurantiacus DSM $18675^{\mathrm{T}}$

- Salisediminibacterium halotolerans DSM $26530^{\mathrm{T}}$

Anaerobacillus arseniciselenatis DSM $15340^{\mathrm{T}}$

Tuberibacillus calidus DSM $17572^{\mathrm{T}}$

- Sporolactobacillus laevolacticus DSM $442^{\mathrm{T}}$

- Novibacillus thermophilus KCTC $33118^{\mathrm{T}}$

Thermoflavimicrobium dichotomicum DSM $44778^{\mathrm{T}}$

Lihuaxuella thermophila DSM $4670^{\mathrm{T}}$

- Laceyella sediminis DSM $45262^{\mathrm{T}}$

Thermoactinomyces vulgaris DSM $43016^{\mathrm{T}}$

Risungbinella massiliensis DSM 44691

Shimazuella kribbensis DSM 45090 ${ }^{\mathrm{T}}$

Seinonella peptonophila DSM $44666^{\mathrm{T}}$

Planifilum fimeticola DSM 44946 ${ }^{\mathrm{T}}$

Melghirimyces thermohalophilus DSM $45514^{\mathrm{T}}$

- Kroppenstedtia eburnea DSM 45196 ${ }^{\mathrm{T}}$

- Desmospora active DSM $45169^{\mathrm{T}}$

Marininema mesophilum DSM $45610^{\mathrm{T}}$

Aneurinibacillus migulanus DSM $2895^{\mathrm{T}}$

- Brevibacillus brevis DSM $30^{\mathrm{T}}$

Cohnella thermotolerans DSM $17683^{\mathrm{T}}$

Thermobacillus composti DSM $18247^{\mathrm{T}}$

- Paenibacillus polymyxa DSM $36^{\mathrm{T}}$

Fontibacillus panacisegetis DSM $28129^{\mathrm{T}}$

- Saccharibacillus sacchari DSM $19268^{\mathrm{T}}$

- Alicyclobacillus acidocaldarius DSM $446^{\mathrm{T}}$

- Kyrpidia tusciae DSM 2912 ${ }^{\mathrm{T}}$

- Effusibacillus lacus DSM $27172^{\mathrm{T}}$

Tumebacillus permanentifrigoris DSM $18773^{\mathrm{T}}$

Thermicanus aegyptius DSM $12793^{\mathrm{T}}$

Tepidibacillus decaturensis DSM $103037^{\mathrm{T}}$

Vulcanibacillus modesticaldus DSM $14931^{\mathrm{T}}$

Figure S2 Desulfuribacillus alkaliarsenatis DSM $24608^{\mathrm{T}}$ 
\begin{aligned} \hline \\ \cline { 2 - 3 } \\ Carnobococterium m divergens DSM $20623^{\mathrm{T}}\end{aligned}$ Aerococcus viridans DSM $20340^{\mathrm{T}}$ - Streptococcus pyogenes DSM $20565^{\mathrm{T}}$ Lactobacillus delbrueckii DSM $20074^{\mathrm{T}}$ Leuconostoc mesenteroides DSM $20343^{T}$ - Gemella haemolysans ATCC 10379

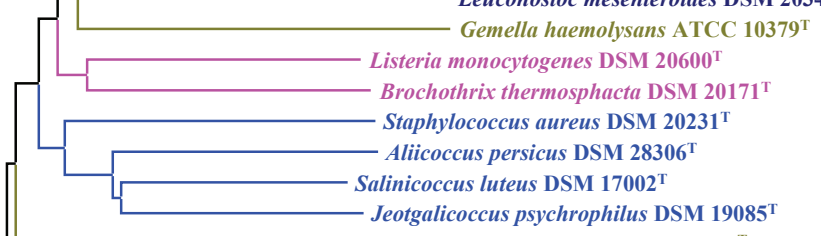
(1)

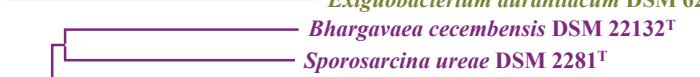

Viridibacillus arvi DSM

Lysinibacillus boronitolerans DSM $17140^{\mathrm{T}}$ Caryophanon latum DSM 14151 - Solibacillus silvestris DSM $12223^{\mathrm{T}}$ Kurthia zopfii DSM 20580 - Psychrobacillus insolitus DSM $5^{\mathrm{T}}$

- Paenisporosarcina quisquiliarum JCM $14041^{\mathrm{T}}$ Planococcus rifietoensis DSM $15069^{\mathrm{T}}$

- Planomicrobium glaciei DSM $24857^{\mathrm{T}}$

- Jeotgalibacillus alimentarius DSM $18867^{\mathrm{T}}$

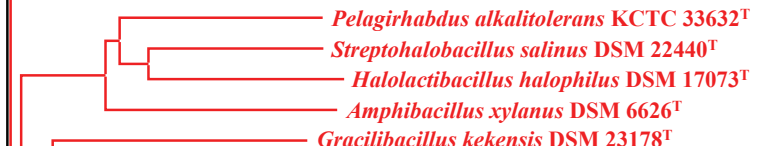
Gracilibacillus kekensis DSM 23178

Sediminibacillus halophilus DSM $18088^{\mathrm{T}}$ - Terribacillus saccharophilus DSM $21619^{\mathrm{T}}$

- Lentibacillus halodurans DSM $18342^{\mathrm{T}}$

Oceanobacillus iheyensis DSM $14371^{\mathrm{T}}$

- Virgibacillus pantothenticus DSM 26

- Paucisalibacillus globulus DSM $18846^{\mathrm{T}}$ Ornithinibacillus californiensis DSM $16627^{\mathrm{T}}$

Tenuibacillus multivorans NBRC $100370^{\mathrm{T}}$

Piscibacillus halophilus DSM 21633 ${ }^{\mathrm{T}}$

Halalkalibacillus halophilus DSM 18494

Salinibacillus aidingensis JCM $12390^{\mathrm{T}}$

Pontibacillus chungwhensis DSM $16287^{\mathrm{T}}$

Thalassobacillus cyri DSM $21635^{\mathrm{T}}$

Halobacillus halophilus DSM $2266^{\mathrm{T}}$

Salimicrobium album DSM $20748^{\mathrm{T}}$

- Natribacillus halophilus DSM $21771^{\mathrm{T}}$

Salsuginibacillus kocurii DSM $18087^{\mathrm{T}}$ - Alteribacillus bidgolensis DSM $25260^{\mathrm{T}}$

Sinobaca qinghaiensis DSM $17008^{\mathrm{T}}$

Marinococcus halophilus DSM 20408T

Salipaludibacillus aurantiacus DSM $18675^{\mathrm{T}}$

Salisediminibacterium halotolerans DSM $26530^{\mathrm{T}}$

- Anaerobacillus arseniciselenatis DSM $15340^{\mathrm{T}}$ Domibacillus robiginosus DSM $25058^{\mathrm{T}}$ Bacillus subtilis DSM $10^{\mathrm{T}}$

Anoxybacillus pushchinoensis DSM $12423^{\mathrm{T}}$

Geobacillus stearothermophilus DSM $22^{\mathrm{T}}$

Parageobacillus thermoglucosidasius DSM $2542^{\mathrm{T}}$

Aeribacillus pallidus DSM $3670^{\mathrm{T}}$

Caldibacillus debilis DSM $16016^{\mathrm{T}}$

Tuberibacillus calidus DSM $17572^{\mathrm{T}}$

Sporolactobacillus laevolacticus DSM 442

Novibacillus thermophilus KCTC $33118^{\mathrm{T}}$

- Thermoflavimicrobium dichotomicum DSM $44778^{\mathrm{T}}$

Lihuaxuella thermophila DSM 4670 ${ }^{\mathrm{T}}$

Laceyella sediminis DSM $45262^{\mathrm{T}}$

Thermoactinomyces vulgaris DSM $43016^{\mathrm{T}}$

Risungbinella massiliensis DSM $44691^{\mathrm{T}}$ Shimazuella kribbensis DSM 45090 ${ }^{\mathrm{T}}$ - Seinonella peptonophila DSM $44666^{\mathrm{T}}$ - Planifilum fimeticola DSM 44946

- Melghirimyces thermohalophilus DSM 45514 ${ }^{\mathrm{T}}$

Kroppenstedtia eburnea DSM 45196

Desmospora activa DSM $45169^{\mathrm{T}}$

Marininema mesophilum DSM $45610^{\mathrm{T}}$

- Aneurinibacillus migulanus DSM 2895 ${ }^{\mathrm{T}}$

Brevibacillus brevis DSM $30^{\mathrm{T}}$

Cohnella thermotolerans DSM $17683^{\mathrm{T}}$

Thermobacillus composti DSM $18247^{\mathrm{T}}$

Fontibacillus panacisegetis DSM $28129^{\mathrm{T}}$

Paenibacillus polymyxa DSM $36^{\mathrm{T}}$

Saccharibacillus sacchari DSM $19268^{\mathrm{T}}$

Alicyclobacillus acidocaldarius DSM $446^{\mathrm{T}}$

- Kyrpidia tusciae DSM $2912^{\mathrm{T}}$

Effusibacillus lacus DSM 27172

- Tumebacillus permanentifrigoris DSM $18773^{\mathrm{T}}$

Thermicanus aegyptius DSM 12793

Tepidibacillus decaturensis DSM $103037^{\mathrm{T}}$

Vulcanibacillus modesticaldus DSM $14931^{\mathrm{T}}$ 


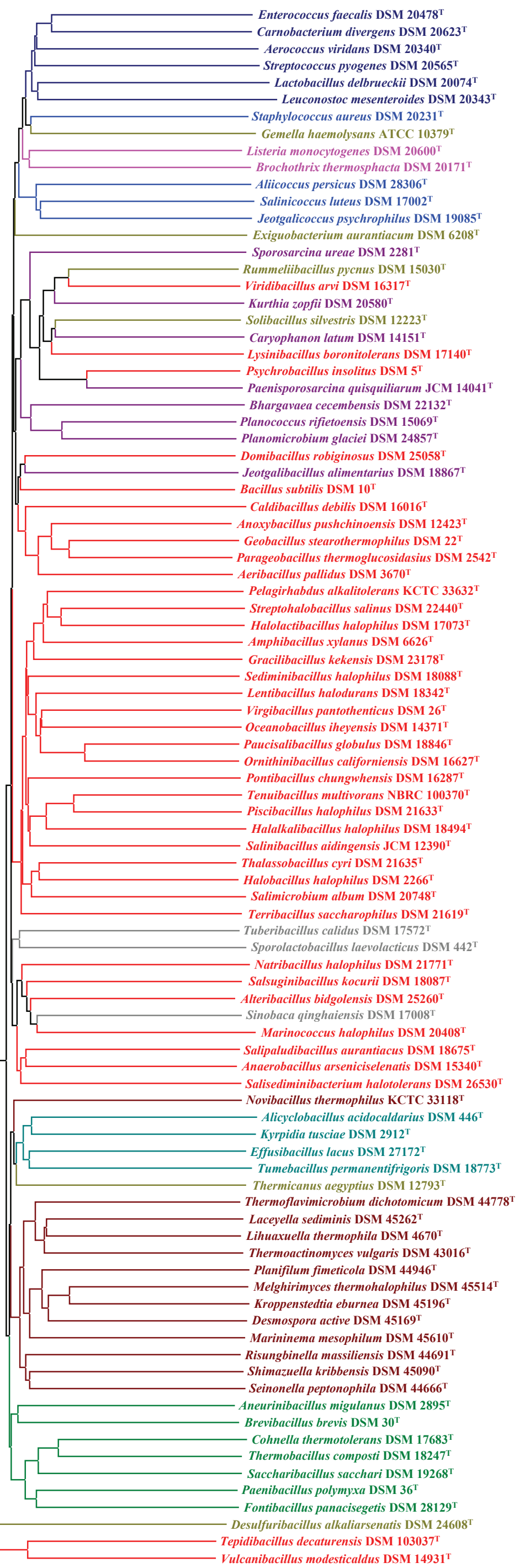


Sporolactobacillus laevolacticus DSM $442^{\mathrm{T}}$

Viridibacillus arvi DSM $16317^{\mathrm{T}}$

Salinicoccus luteus DSM 17002

Halolactibacillus halophilus DSM $17073^{\mathrm{T}}$

Paucisalibacillus globulus DSM $18846^{\mathrm{T}}$

Exiguobacterium aurantiacum DSM $6208^{\mathrm{T}}$

Paenisporosarcina quisquiliarum JCM $14041^{\mathrm{T}}$

- Lentibacillus halodurans DSM $18342^{\mathrm{T}}$

Parageobacillus thermoglucosidasius DSM $2542^{\mathrm{T}}$

Gracilibacillus kekensis DSM $23178^{\mathrm{T}}$

Laceyella sediminis DSM $45262^{\mathrm{T}}$

- Gemella haemolysans ATCC $10379^{\mathrm{T}}$

Kurthia zopfii DSM 20580
Sediminibacillus halophilus DSM $18088^{\mathrm{T}}$ Lysinibacillus boronitolerans DSM $17140^{\mathrm{T}}$

Novibacillus thermophilus KCTC $33118^{\mathrm{T}}$

Thermoflavimicrobium dichotomicum DSM $44778^{\mathrm{T}}$

Desulfuribacillus alkaliarsenatis DSM $24608^{\mathrm{T}}$ Jeotgalicoccus psychrophilus DSM $19085^{\mathrm{T}}$

Anoxybacillus pushchinoensis DSM $12423^{\mathrm{T}}$

Saccharibacillus sacchari DSM $19268^{\mathrm{T}}$

Alicyclobacillus acidocaldarius DSM $446^{\mathrm{T}}$

Effusibacillus lacus DSM 27172

Kyrpidia tusciae DSM $2912^{\mathrm{T}}$

Halobacillus halophilus DSM 2266 ${ }^{\mathrm{T}}$

Psychrobacillus insolitus DSM $5^{\mathrm{T}}$

- Brevibacillus brevis DSM 30 ${ }^{\mathrm{T}}$

Vulcanibacillus modesticaldus DSM $14931^{\mathrm{T}}$

Geobacillus stearothermophilus DSM $22^{\mathrm{T}}$ - Sporosarcina ureae DSM $2281^{\mathrm{T}}$

Shimazuella kribbensis DSM 45090 ${ }^{\mathrm{T}}$

Alteribacillus bidgolensis DSM $25260^{\mathrm{T}}$ - Brochothrix thermosphacta DSM $20171^{\mathrm{T}}$

- Salimicrobium album DSM 20748

Marinococcus halophilus DSM $20408^{\mathrm{T}}$ - Streptohalobacillus salinus DSM $22440^{\mathrm{T}}$

- Caldibacillus debilis DSM $16016^{\mathrm{T}}$

- Marininema mesophilum DSM $45610^{\mathrm{T}}$

Seinonella peptonophila DSM $44666^{\mathrm{T}}$

- Halalkalibacillus halophilus DSM 18494

Paenibacillus polymyxa DSM $36^{\mathrm{T}}$

- Piscibacillus halophilus DSM $21633^{\mathrm{T}}$

Kroppenstedtia eburnea DSM 45196 ${ }^{\mathrm{T}}$

Risungbinella massiliensis DSM 44691

- Listeria monocytogenes DSM $20600^{\mathrm{T}}$

Sinobaca qinghaiensis DSM $17008^{\mathrm{T}}$

Pelagirhabdus alkalitolerans KCTC $33632^{\mathrm{T}}$

Staphylococcus aureus DSM $20231^{\mathrm{T}}$

Thalassobacillus cyri DSM $21635^{\mathrm{T}}$

Bacillus subtilis DSM $10^{\mathrm{T}}$

Virgibacillus pantothenticus DSM $26^{\mathrm{T}}$

Bhargavaea cecembensis DSM $22132^{\mathrm{T}}$

Rummeliibacillus pycnus DSM $15030^{\mathrm{T}}$

Tenuibacillus multivorans NBRC $100370^{\mathrm{T}}$

Aeribacillus pallidus DSM $3670^{\mathrm{T}}$

Planococcus rifietoensis DSM $15069^{\mathrm{T}}$

Oceanobacillus iheyensis DSM $14371^{\mathrm{T}}$

Melghirimyces thermohalophilus DSM $45514^{\mathrm{T}}$ Aliicoccus persicus DSM $28306^{\mathrm{T}}$

Domibacillus robiginosus DSM $25058^{\mathrm{T}}$

Lactobacillus delbrueckii DSM 20074

- Salinibacillus kushneri JCM $12390^{\mathrm{T}}$

Carnobacterium divergens DSM $20623^{\mathrm{T}}$

Solibacillus silvestris DSM $12223^{\mathrm{T}}$

Pontibacillus chungwhensis DSM $16287^{\mathrm{T}}$

Tumebacillus permanentifrigoris DSM $18773^{\mathrm{T}}$

Amphibacillus xylanus DSM $6626^{\mathrm{T}}$

Jeotgalibacillus alimentarius DSM $18867^{\mathrm{T}}$

Thermoactinomyces vulgaris DSM 43016 ${ }^{\mathrm{T}}$

- Ornithinibacillus californiensis DSM $16627^{\mathrm{T}}$

Enterococcus faecalis DSM 20478

Streptococcus pyogenes DSM $20565^{\mathrm{T}}$

Terribacillus saccharophilus DSM $21619^{\mathrm{T}}$

Tuberibacillus calidus DSM $17572^{\mathrm{T}}$

Aerococcus viridans DSM 20340 ${ }^{\mathrm{T}}$

- Salsuginibacillus kocurii DSM $18087^{\mathrm{T}}$

Planifilum fimeticola DSM $44946^{\mathrm{T}}$

Planomicrobium glaciei DSM $24857^{\mathrm{T}}$

Aneurinibacillus migulanus DSM $2895^{\mathrm{T}}$

Caryophanon latum DSM $14151^{\mathrm{T}}$

Thermicanus aegyptius DSM $12793^{\mathrm{T}}$

Cohnella thermotolerans DSM $17683^{\mathrm{T}}$

Leuconostoc mesenteroides DSM $20343^{\mathrm{T}}$

Natribacillus halophilus DSM $21771^{\mathrm{T}}$

- Fontibacillus panacisegetis DSM $28129^{\mathrm{T}}$

Desmospora activa DSM $45169^{\mathrm{T}}$

Salipaludibacillus aurantiacus DSM $18675^{\mathrm{T}}$

Anaerobacillus arseniciselenatis DSM $15340^{\mathrm{T}}$

Thermobacillus composti DSM $18247^{\mathrm{T}}$

Lihuaxuella thermophila DSM 4670

Tepidibacillus decaturensis DSM $103037^{\mathrm{T}}$ 